\title{
Fire dynamics during the 20th century simulated by the Community Land Model
}

\author{
S. Kloster ${ }^{1, *}$, N. M. Mahowald ${ }^{1}$, J. T. Randerson ${ }^{2}$, P. E. Thornton ${ }^{3}$, F. M. Hoffman ${ }^{3}$, S. Levis ${ }^{4}$, P. J. Lawrence ${ }^{4}$, \\ J. J. Feddema ${ }^{5}$, K. W. Oleson ${ }^{4}$, and D. M. Lawrence ${ }^{4}$ \\ ${ }^{1}$ Earth and Atmospheric Sciences, Cornell University, Ithaca, NY, USA \\ ${ }^{2}$ Department of Earth System Science, University of California, Irvine, CA, USA \\ ${ }^{3}$ Climate and Ecosystem Processes, Environmental Science Division, Oak Ridge National Laboratory, Oak Ridge, TN, USA \\ ${ }^{4}$ Climate and Global Dynamics Division, National Center for Atmospheric Research, Boulder, CO, USA \\ ${ }^{5}$ Department of Geography, University of Kansas, Lawrence, KA, USA \\ *now at: Land in the Earth System, Max Planck Institute for Meteorology, Hamburg, Germany
}

Received: 16 November 2009 - Published in Biogeosciences Discuss.: 26 January 2010

Revised: 23 April 2010 - Accepted: 10 May 2010 - Published: 11 June 2010

\begin{abstract}
Fire is an integral Earth System process that interacts with climate in multiple ways. Here we assessed the parametrization of fires in the Community Land Model (CLM-CN) and improved the ability of the model to reproduce contemporary global patterns of burned areas and fire emissions. In addition to wildfires we extended CLM$\mathrm{CN}$ to account for fires related to deforestation. We compared contemporary fire carbon emissions predicted by the model to satellite-based estimates in terms of magnitude and spatial extent as well as interannual and seasonal variability. Long-term trends during the 20th century were compared with historical estimates. Overall we found the best agreement between simulation and observations for the fire parametrization based on the work by Arora and Boer (2005). We obtained substantial improvement when we explicitly considered human caused ignition and fire suppression as a function of population density. Simulated fire carbon emissions ranged between 2.0 and $2.4 \mathrm{Pg} \mathrm{C} /$ year for the period 1997-2004. Regionally the simulations had a low bias over Africa and a high bias over South America when compared to satellite-based products. The net terrestrial carbon source due to land use change for the $1990 \mathrm{~s}$ was $1.2 \mathrm{Pg} \mathrm{C} /$ year with $11 \%$ stemming from deforestation fires. During 2000-2004 this flux decreased to $0.85 \mathrm{PgC} /$ year with a similar relative contribution from deforestation fires. Between 1900 and 1960 we predicted a slight downward trend in global
\end{abstract}

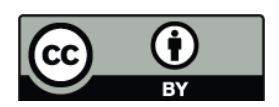

Correspondence to: S. Kloster (silvia.kloster@zmaw.de) fire emissions caused by reduced fuels as a consequence of wood harvesting and also by increases in fire suppression. The model predicted an upward trend during the last three decades of the 20th century as a result of climate variations and large burning events associated with ENSOinduced drought conditions.

\section{Introduction}

Fires occur in all major biomes and influence climate in multiple ways. Fires lead to the emissions of trace gases and aerosols into the atmosphere impacting atmospheric chemistry (Crutzen et al., 1979), atmospheric radiative properties (Penner et al., 1992), and cloud formation (Feingold et al., 2001; Andreae et al., 2004). In addition, fires impact land surface energy fluxes (Liu and Randerson, 2008) and influence species composition, including the balance between forest, shrub, and grass plant functional types (Bond et al., 2004; Chambers et al., 2005). These changes in community composition, along with human and climate factors, regulate burned area and fire emissions at a regional scale (Power et al., 2008). Changes in climate are expected to influence the fire regime in multiple ways, including changes in fire season length and fire intensity, but also changes in species composition, fuels, and patterns of land management. Subsequent emissions and modification of the land surface energy budget are expected to feedback in both positive and negative ways with the climate (Bowman et al., 2009).

Published by Copernicus Publications on behalf of the European Geosciences Union. 
Progress in understanding and monitoring fires has been made in recent years by the use of satellite observations to derive global burned area estimates (Giglio et al., 2006; Tansey et al., 2008). Although global fire emission estimates have improved significantly with the use of satellite-based burned area products, uncertainty levels remain high at regional scales, because of incomplete information and parametrization of fuel loads, combustion completeness, and emission factors (Kasischke and Penner, 2004). Satellite-based fire products that cover a multi-year timespan are valuable tools for evaluating the capability of fire models to simulate fires globally particularly with respect to spatial and temporal patterns of fire activity.

A few models have been developed to prognostically simulate fire distributions in global vegetation models. Thonicke et al. (2001) relate area burned and fire season length by an empirically-derived relationship. Arora and Boer (2005) introduce a process based approach by parameterizing area burned as a function of the fire spread rate. Pechony and Shindell (2009) developed a global-scale fire parametrization for fire favorable environmental conditions based on water vapor pressure deficits. Given the complexity of fires, these global-scale models are necessarily incomplete and more data will be needed in the future to constrain more mechanistic parametrizations of fire processes.

In this study we modified the global representation of fires in the biogeochemical model CLM-CN (Thornton et al., 2009) based on the work by Thonicke et al. (2001) and Arora and Boer (2005). Our goal in this study was to best match the observed spatial and temporal variability of fires for the contemporary time period, and to predict how fires have changed during the 20th century.

In the deforestation process fire is often used as a tool for land clearing to accelerate the speed of conversion to agriculture (van der Werf et al., 2009). Deforestation fires contribute to contemporary fire emissions mainly in tropical regions (van der Werf et al., 2006; Page et al., 2002), but are a highly spatially variable source over the last century. In this study, we used CLM-CN with prescribed dynamic land use datasets (Hurtt et al., 2006) to explicitly account for the fraction of deforestation emissions that occurs through burning. This allowed us to compare simulated contemporary fire carbon emissions to satellite-based estimates, that capture both wildfires and deforestation fires. We also added the active role humans have in modulating wildfires either by igniting or suppressing fires (Robin et al., 2006; Stocks et al., 2003), assuming that this can be parametrized as a function of population density.

For this study we performed offline CLM-CN simulations for 1798 to 2004 and compared simulated contemporary area burned and fire carbon emissions to satellite-based global fire products (van der Werf et al., 2006; Schultz et al., 2008; Tansey et al., 2008; Mieville et al., 2010). In addition, we performed several sensitivity studies to disentangle the impact of climate change, change in population density and land use change and wood harvest on the simulated fire carbon emissions to explain the simulated trend over the last century. Due to the limited time coverage of the re-analysis data used in this study to force CLM-CN (Qian et al., 2006) we only accounted for varying climate between 1948 and 2004, which, however, includes most of the anthropogenically derived climate change. The results presented here are the first fully consistent modeling attempt to globally estimate changes in fires driven by changes in population density, land use and climate over such a long time period.

The paper is structured as follows. Section 2 briefly describes the model used in this study. A more detailed description of the different fire algorithms used and the treatment of deforestation fires can be found in the Appendix A. Sect. 3 summarizes the simulations performed in this study and the observations used for an evaluation of the results. Results for contemporary time periods are discussed and compared to observations in Sect. 4, including comparisons with burned area and emissions on seasonal and interannual time scales. Sect. 5 evaluates the trend in fire carbon emissions as simulated for the 20th century together with a sensitivity analysis of simulated emissions to climate, population density, and land use conversion (Sect. 5.1). Sect. 6 provides a summary of the results together with concluding remarks.

\section{Model description}

All simulations in this study were performed with a modified version of the Community Land Model version 3.5 (CLM3.5; Oleson et al., 2008b; Stoeckli et al., 2008) applied with a resolution of $1.9^{\circ} \times 2.5^{\circ}$. The modifications of the model physics beyond CLM3.5 incorporate most of the updates of the model that will make up CLM version 4 and include revisions to the hydrology scheme (Decker and Zeng, 2009; Sakaguchi and Zeng, 2009), a modified snow model including aerosol deposition, vertically resolved snow pack heating, a density-dependent snow cover fraction parametrization, and a revised snow burial fraction over short vegetation (Niu and Yang, 2007; Flanner and Zender, 2005, 2006; Flanner et al., 2007; Wang and Zeng, 2009; Lawrence and Slater, 2009), a representation of the thermal and hydraulic properties of organic soil (Lawrence and Slater, 2008a), a 20$\mathrm{m}$ deep ground column (Lawrence et al., 2008b), and an urban model (Oleson et al., 2008a). The plant functional type (PFT) distribution is as in Lawrence and Chase (2007) except that a new cropping dataset is used (Ramankutty et al., 2008) and a grass PFT restriction has been put in place to reduce a high grass PFT bias in forested regions by replacing the herbaceous fraction with low trees rather than grass. Taken together, the augmentations to CLM3.5 result in improved soil moisture dynamics that lead to higher soil moisture variability and drier soils. Excessively wet and unvarying soil moisture was recognized as a deficiency in CLM3.5 (Oleson et al., 2008b; Decker and Zeng, 2009). The revised 
model also simulates, on average, higher snow cover, cooler soil temperatures in organic-rich soils, higher global river discharge, lower albedos over forests and grasslands, and higher transition-season albedos in snow covered regions, all of which are improvements compared to CLM3.5.

Additionally, the model is extended with a carbon-nitrogen biogeochemical model (Thornton et al., 2007, 2009; Randerson et al., 2009) hereafter referred to as CLM-CN. CN is based on the terrestrial biogeochemistry Biome-BGC model with prognostic carbon and nitrogen cycle (Thornton et al., 2002; Thornton and Rosenbloom, 2005). CLM-CN dynamically accounts for carbon and nitrogen state variables and fluxes in vegetation, litter, and soil organic matter. It retains the prognostic estimation of water and energy in the vegetation-snow-soil column from CLM. Detailed description of the biogeochemical component of CLM-CN can be found in Thornton et al. (2007).

The original version of CLM-CN includes a prognostic treatment of fires based on the fire algorithm by Thonicke et al. (2001) (CLM-CN-T), which was originally developed for the LPJ (Lund-Potsdam-Jena) model (Sitch et al., 2003). In this study we modified the representation of wildland fires in CLM-CN by a fire algorithm based on the work by Arora and Boer (2005) (CLM-CN-AB), which was developed within the Canadian Terrestrial Ecosystem Model (CTEM) framework (Verseghy et al., 1993).

In both the Thonicke et al. (2001) and Arora and Boer (2005) algorithms, the first step is to estimate burned area using information about climate and fuel loads. Then fire carbon fluxes to the atmosphere $(E)$ are related to combustion and mortality following:

$E=A \cdot C \cdot \mathrm{cc} \cdot \mathrm{mort}$

with $A$ representing the area burned, $C$ the carbon pool sizes for the different fuel types considered in CLM-CN, "cc" the combustion completeness, and "mort" the mortality factor. "cc" and "mort" were different for each plant functional types (PFTs) within CLM-CN. While Thonicke et al. (2001) use an empirical relationship relating fire season length and burned area, Arora and Boer (2005) introduce a process based fire parametrization simulating area burned as a function of fire spread rate. Both algorithms differ in their assumptions made for combustion completeness and mortality factors. The implementation of the two fire algorithms into CLM-CN is described in detail in Appendix A.

We modified the dynamic land cover treatment in CLM$\mathrm{CN}$ to account for deforestation fires in relation to fire probabilities simulated in the individual fire algorithms (details can be found in the Appendix A5). We further extended the CLM-CN-AB version by an explicit treatment of human ignition following Venesky et al. (2002), for which the probability of human ignition increases with population density. For fire suppression we also assumed a population density dependency, with the highest fire suppression rate (90\%) in densely populated areas (more information is provided in Appendix A4).

\section{Simulations and observations}

We performed a series of simulations to test the performance of the two fire algorithms (Thonicke et al., 2001; Arora and Boer, 2005) implemented in CLM-CN in combination with several sensitivity simulations to disentangle the importance of the individual forcing factors (climate, population density, land use change and wood harvest). All simulations were offline simulations in which CLM-CN was forced by a prescribed data set of atmospheric fluxes and states. Table 1 summarizes the simulations performed for this study.

All transient simulations branched from control simulations (205 years) using CLM-CN with the Thonicke et al. (2001) fire algorithm (C-T) or with the Arora and Boer (2005) fire algorithm (C-AB, C-AB-HI, C-AB-HI-FS). For the control simulations each version of the model was allowed to reach steady state with respect to the prescribed forcing data. For our implementation of the Arora and Boer (2005) algorithm we assumed a constant human ignition probability as done in the original Arora and Boer (2005) publication $(\mathrm{C}-\mathrm{AB})$. Alternatively we performed simulations in which the human ignition probability was made a function of population density (C-AB-HI) and where both human ignition and suppression were included (C-AB-HI-FS). Appendix A4 describes in detail how we parametrized human ignition and fire suppression as a function of population density. In all control simulations atmospheric $\mathrm{CO}_{2}$ concentration, nitrogen deposition and land cover (Hurtt et al., 2006) were set to pre-industrial values. As climate forcing a repeating cycle of the first 25 years (1948-1972) of National Centers for Environmental Prediction/National Center for Atmospheric Research (NCEP/NCAR) reanalysis data (Qian et al., 2006) was used. The simulations that took into account human ignition and fire suppression as a function of population density (C-AB-HI and C-AB-HI-FS) used population density data representative for the year 1850 throughout the simulation period (Klein Goldewijk, 2001). The nitrogen deposition used in these simulations had a high global total (25\%) compared to previous studies (Lamarque et al., 2005). Sensitivity studies with nitrogen depositions following Lamarque et al. (2005), that will be the standard field used in future CLM-CN simulations, showed changes in fire carbon emissions by less than $2 \%$ for the global total and only a few regions showed higher deviations with maximum levels not exceeding $10 \%$.

Starting from the control simulations we conducted correspondent transient simulations (T-FULL, AB-FULL, AB-HI, AB-HI-FS) from 1798 to 2004 with transient time-varying atmospheric $\mathrm{CO}_{2}$ concentrations, population density, nitrogen deposition, land use change and wood harvest and cyclic 1948-1972 NCEP/NCAR forcing until 1972. From 1973 
Table 1. Control and transient model simulations analyzed in the present study. Simulations used different fire algorithms, different treatment of human ignition potential, and different assumptions about land-cover change and wood harvest as well as climate forcing.

\begin{tabular}{|c|c|c|c|c|c|c|}
\hline Name & Fire algorithm ${ }^{\mathrm{a}}$ & Human ignition $^{\mathrm{b}}$ & Pop. density ${ }^{c}$ & $\begin{array}{l}\text { Land-cover } \\
\text { change }^{\mathrm{d}}\end{array}$ & $\begin{array}{l}\mathrm{CO}_{2} \text { concentration/ } \\
\text { Nitrogen deposition }\end{array}$ & Climate forcing ${ }^{f}$ \\
\hline \multicolumn{7}{|c|}{ Control simulations } \\
\hline $\mathrm{C}-\mathrm{AB}$ & Arora and Boer & constant $=0.5$ & - & - & pre-industrial & 1948-1972 \\
\hline C-AB-HI & Arora and Boer & human ignition & pre-industrial & - & pre-industrial & 1948-1972 \\
\hline C-AB-HI-FS & Arora and Boer & human ign. and fire suppr. & pre-industrial & - & pre-industrial & 1948-1972 \\
\hline T-FULL & Thonicke & - & - & transient & transient & 1948-1972/1973-2004 \\
\hline AB-FULL & Arora and Boer & constant $=0.5$ & - & transient & transient & 1948-1972/1973-2004 \\
\hline AB-HI & Arora and Boer & human ignition & transient & transient & transient & 1948-1972/1973-2004 \\
\hline AB-HI-FS & Arora and Boer & human ign. and fire suppr. & transient & transient & transient & 1948-1972/1973-2004 \\
\hline \multicolumn{7}{|c|}{ Sensitivity simulations: 1798-2004 } \\
\hline
\end{tabular}

${ }^{a}$ Fire algorithm in CLM-CN based on Thonicke et al. (2001) or Arora and Boer (2005).

$\mathrm{b}$ different treatment of human ignition: either a constant value of 0.5 (constant), allowing for human ignition as a function of population density (HI), or human ignition and fire suppression (HI-FS).

${ }^{c}$ Population density was allowed to vary between 1798 and 2004 (Klein Goldewijk, 2001) or was held constant at a pre-industrial value (PI).

${ }^{\mathrm{d}}$ Land cover change and wood harvest: either no land cover change and wood harvest (-) or transient land cover change and wood harvest between 1850-2004 (Hurtt et al., 2006).

${ }^{\text {e }} \mathrm{CO}_{2}$ concentration and nitrogen deposition were set to pre-industrial values for the control simulations and were transient time-varying for the transient simulations.

f Climate forcing: either cycling periodically through NCEP/NCAR data (Qian et al., 2006) for the years 1948-1972 or cycling through 1948-1972 followed by the full time series for the years 1948-2004.

onwards NCEP/NCAR forcing was used corresponding to the model simulation year as done in Randerson et al. (2009).

In addition to the transient simulations that were driven with the full set of transient forcings we performed a series of sensitivity simulations in which individual forcing factors were kept constant at their pre-industrial values. These included the simulation AB-LUC in which land use and wood harvest were held constant at the 1850 level and AB-CLIM in which the NCEP/NCAR forcing consisted of the 25 year repeat cycle (1948-1972) throughout the simulation period. Two more sensitivity simulations were conducted for the case in which human ignition (AB-HI-PI) and human ignition and fire suppression (AB-HI-FS-PI) were taken into account as a function of population density using constant population density data representative for the year 1850 .

To evaluate the simulated burned area and fire carbon emissions we used satellite-based fire products for the contemporary period. The simulated trend over the 20th century was compared with long-term time series derived from historical records.
In recent years a number of global satellite derived burned area products have been developed, including GLOBSCAR (Simon et al., 2004), Global Burned Area 2000 (GBA2000, Gregoire et al., 2002), GlobCarbon (Plummer et al., 2006), MODIS Collection 5 (Roy et al., 2008), L3JRC (Tansey et al., 2008), and the Global Fire Emission Database (GFEDv2, Giglio et al. (2006)). In this study we compared our results to the publicly available satellite-based estimates reported in GFEDv2 (van der Werf et al., 2006), the recently published L3JRC product (Tansey et al., 2008), and GICC estimates (Mieville et al., 2010) spanning multi-year time periods.

GFEDv2 reports area burned along with fire carbon emissions on a monthly basis with $1^{\circ}$ by $1^{\circ}$ resolution for the time period 1997-2004. Area burned estimates are derived for 2001 to 2004 from MODIS active fire observations and were extended back through 1997 using ATSR and VIRS satellite data (Giglio et al., 2006). The area burned estimates are embedded into a global biogeochemical model (CASA, Carnegie-Ames-Stanford Approach). Direct fire carbon emissions are calculated using an approach similar 

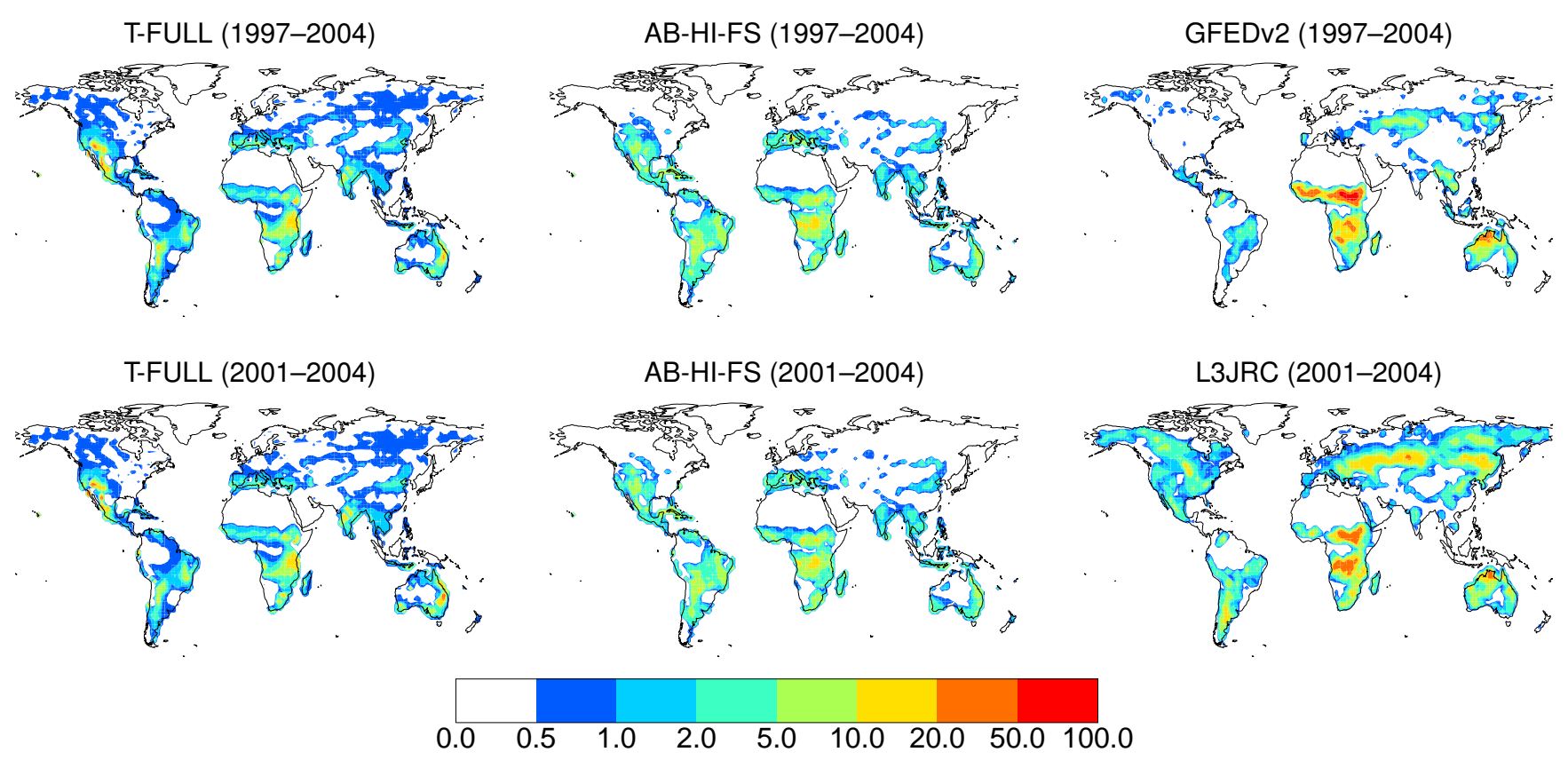

Fig. 1. Simulated annual total (wildfire plus deforestation) area burned [percentage of grid box] compared to satellite-based fire products: GFEDv2 (van der Werf et al., 2006) and L3JRC (Tansey et al., 2008). The model simulations are averaged over the corresponding observational periods (GFEDv2: 1997-2004; L3JRC: 2001-2004). Regional values for all simulations performed are given in Fig. 2.

to the fire algorithms used in this study: as product of area burned, available biomass, fire induced mortality, and a combustion completeness factor. L3JRC reports area burned with a resolution of $1 \mathrm{~km}$ for April 2000 to April 2007 on a daily basis using SPOT VEGETATION reflectance data in combination with a modified version of GBA2000 algorithm. Burned areas were evaluated for selected regions with Landsat TM scenes revealing a significant underestimation of burned area in regions with low vegetation cover. GICC reports fire emissions on an annual basis for the period 19972005 based on satellite products (GBA2000 burned areas, ATSR fire counts), and on the Global Land Cover (GLC) 2000 vegetation map. Emissions are first estimated for year 2000 from GBA2000 burned areas as product of burned areas, biomass densities, burning efficiencies, and emission factors. ATSR fire counts are then used to derive temporal and spatial distribution of fire emissions from the GBA2000 emissions for the period 1997-2004.

Large discrepancies remain between the different satellitebased products (Boschetti et al., 2004; Roy and Boschetti, 2009; Chang and Song, 2009; Giglio et al., 2010). Thus, while we compared our results to the best available observations, there remains a large uncertainty in any fire model evaluation, because of the large uncertainty in the observations.

Long-term observations on fire activity are very sparse (Marlon et al., 2008). Schultz et al. (2008) developed for the RETRO project a fire emission inventory for the period
1960 to 2000 based on different satellite products, a semiphysical fire model and an extensive literature review. We used this product for an evaluation of the mean state, interannual variability, and the trend between 1960 and 2000 . Mouillot et al. (2006) constructed a yearly global burned area product for the 20th century based on published data, land use practices, qualitative reports and local studies, such as tree ring analyses. Mieville et al. (2010) used these trends to derive decadal mean fire emissions by calculating the product of burned areas, biomass densities, burning efficiencies, and emission factors scaled to the contemporary GICC estimates. In the following sections we refer to this product as GICChist.

\section{Fires during the satellite era}

\subsection{Annual area burned and carbon emissions}

We compared global distribution of simulated annual area burned for the simulations T-FULL and AB-HI-FS to estimates given in the L3JRC (Tansey et al., 2008) and GFEDv2 (van der Werf et al., 2006) fire products (Fig. 1). In general the model simulations were able to capture broad spatial patterns across continents. Annual burned areas during 19972004 were between 176 and 330 Mha in the model simulations compared to a mean of 329 Mha from GFEDv2. For the period 2001-2004 the simulations varied between 175 
Table 2. Annual total (wildfire and deforestation) burned areas and fire carbon emissions for Africa (NHAF: Northern Hemisphere Africa, SHAF: Southern Hemisphere Africa) for the different simulations compared to observations. All reported values are averages over the years 2001-2004.

\begin{tabular}{|c|c|c|c|c|c|c|c|}
\hline & L3JRC & GFEDv2 & Lehsten et al. (2009) ${ }^{\mathrm{a}}$ & T-FULL & AB-FULL & AB-HI & AB-HI-FS \\
\hline \multicolumn{8}{|c|}{ area burned [Mha] } \\
\hline SHAF & $87.4 \pm 8.0$ & $80.0 \pm 3.5$ & $112 \pm 1$ & $39.0 \pm 2.6$ & $74.1 \pm 8.0$ & $66.0 \pm 7.3$ & $45.45 \pm 2.5$ \\
\hline NHAF & $68.0 \pm 7.8$ & $139 \pm 10.3$ & $86.7 \pm 9.6$ & $19.5 \pm 0.5$ & $44.5 \pm 2.7$ & $43.8 \pm 3.5$ & $26.4 \pm 5.2$ \\
\hline \multicolumn{8}{|c|}{ carbon loss $[\mathrm{Tg} \mathrm{C} / \mathrm{yr}]$} \\
\hline SHAF & & $577 \pm 14.0$ & $457 \pm 81.8$ & $402 \pm 21.5$ & $504 \pm 38.1$ & $537 \pm 37.6$ & $414 \pm 39.8$ \\
\hline NHAF & & $621 \pm 69.0$ & $280 \pm 36.7$ & $308 \pm 21.2$ & $490 \pm 79.5$ & $510 \pm 88.9$ & $367 \pm 71.3$ \\
\hline
\end{tabular}

a Lehsten et al. (2009) uses burned areas as reported in L3JRC modified by a correction term to compensate for a likely underestimation identified in comparison with higher resolution LANDSAT imagery.

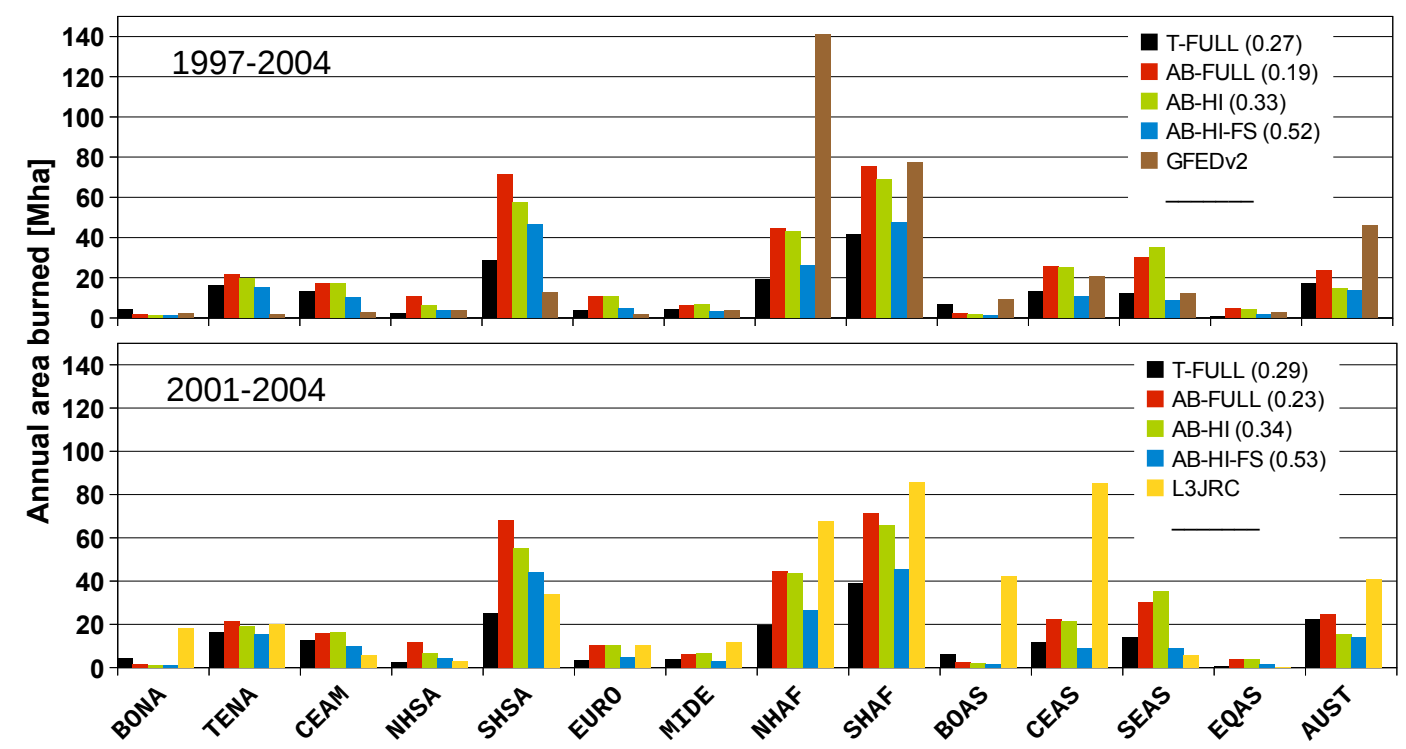

Fig. 2. Annual total area burned (wildfire plus deforestation) in [Mha] for different regions compared to GFEDv2 (van der Werf et al., 2006) and L3JRC (Tansey et al., 2008). The model simulations were averaged over the corresponding observational period (1997-2004, 20012004, respectively). The number in brackets denote spatial correlation coefficients between simulations and satellite-based fire products. Regions are defined in Fig. A3.

and 321 Mha compared to a mean of 401 Mha from L3JRC. Thus, the global annual model estimates were below or near the lower end of the range of the two satellite derived estimates.

Regional averages suggested a large sensitivity of the modeled results to the fire parameterizations used (Fig. 2). Because of the large interannual variability in regional area burned, we show regional averages for the appropriate time periods for each of the satellite derived products. Figure A3 defines the regions used for this analysis.

The highest annual area burned occured in Africa, accounting for between 33 and $40 \%$ of the global total. South America, the second most important region, accounted for between 16 to $27 \%$ of the global total. L3JRC and GFEDv2 estimates show diverging patterns for these two regions.
For Africa, Table 2 compares annual area burned estimates and carbon emissions from Northern and Southern Hemisphere Africa as reported in GFEDv2 and L3JRC averaged over the time period 2001-2004. While L3JRC reports the largest annual area burned in Southern Hemisphere Africa, GFEDv2 shows highest values for Northern Hemisphere Africa. A validation of MODIS, L3JRC and GlobCarbon burned-area products for Southern Hemisphere Africa using independent LANDSAT data revealed a particularly strong underestimation in area burned for the L3JRC product (Roy and Boschetti, 2009) as already noted by Tansey et al. (2008). Lehsten et al. (2009) adjust for this underestimation in the L3JRC product for Africa by assuming that the tree and shrub cover classes are underestimated by 48 and $25 \%$, respectively, resulting in a burned area that is approximately 


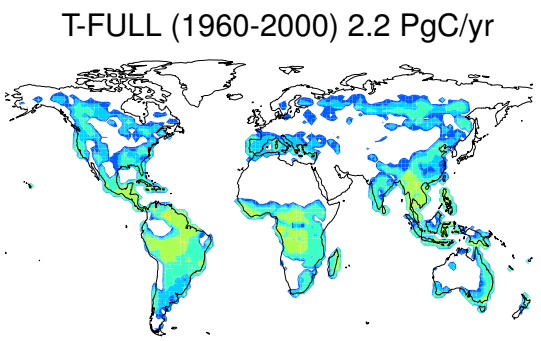

T-FULL (1997-2004) 2.4 PgC/yr

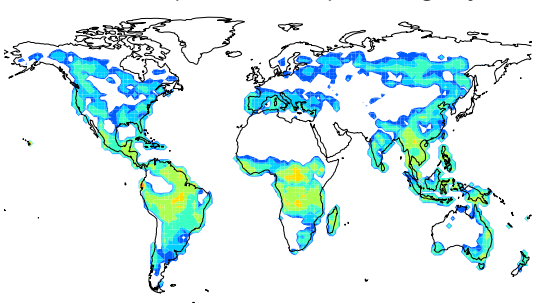

\section{GICC (1997-2004) 2.7 PgC/yr}

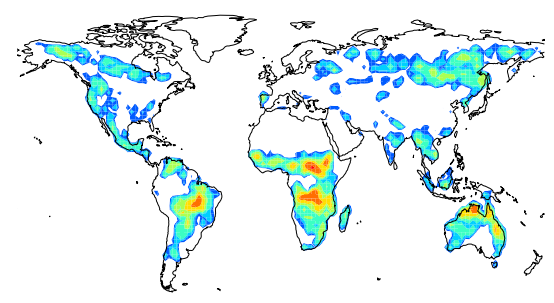

AB-HI-FS (1960-2000) 1.7 PgC/yr

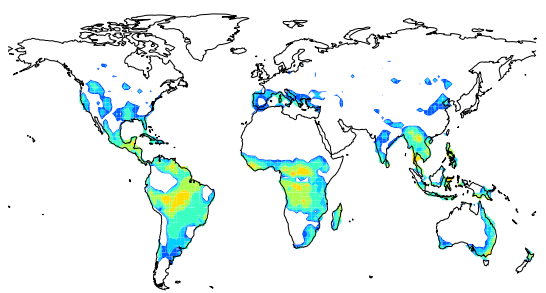

AB-HI-FS (1997-2004) 2.0 PgC/yr

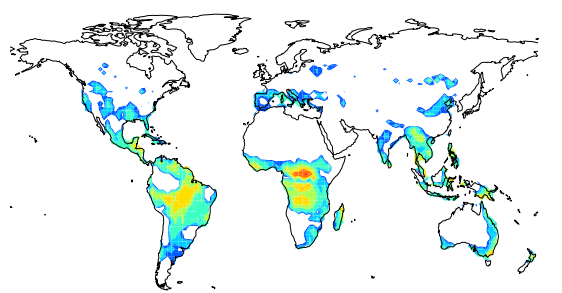

RETRO (1960-2000) 2.0 PgC/yr

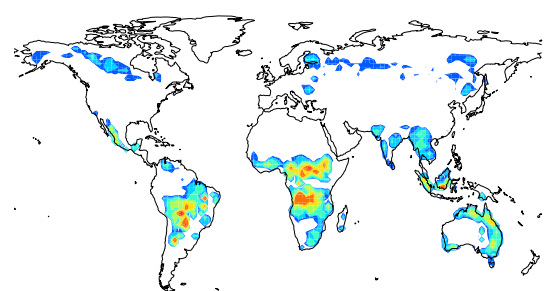

GFEDv2 (1997-2004) 2.3 PgC/yr

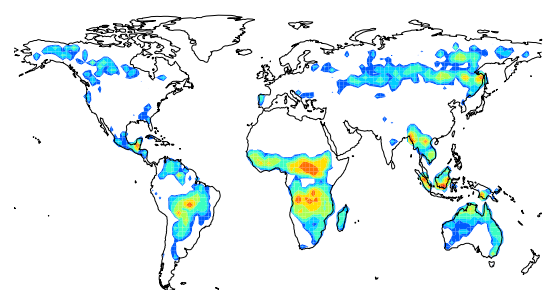

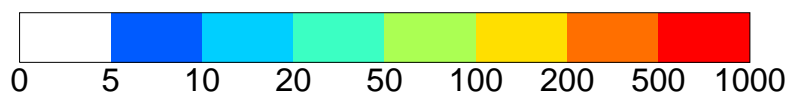

Fig. 3. Annual mean total (wildfire plus deforestation) fire carbon emissions $\left[\mathrm{g} \mathrm{C} / \mathrm{m}^{2} /\right.$ year] compared to emissions reported in the fire products GFEDv2 (van der Werf et al., 2006), RETRO (Schultz et al., 2008) and GICC (Mieville et al., 2010). The model simulations are averaged over the corresponding observational periods (GFEDv2/GICC: 1997-2004; RETRO: 1960-2000). The numbers in the title of each panel are global mean fire emissions with units of PgC/year. Regional values for all simulations performed are given in Fig. 4.

$25 \%$ higher than reported in L3JRC. A study from Ito et al. (2007) based on MODIS burned area reports an annual area burned of 200 Mha for Southern Hemisphere Africa for the same time period. Other estimates range between 58 and 226 Mha for Southern Hemisphere Africa (Ito et al., 2007, and references therein) and 136 and 362 Mha for Northern Hemisphere Africa (Schultz et al., 2008, and references therein). All CLM-CN simulations had a considerably lower annual burned area over the African continent (Northern Hemisphere: 19.5-44.5 Mha; Southern Hemisphere: 39.074.1 Mha).

For South America CLM-CN simulations had higher total annual area burned (31-82 Mha) compared to GFEDv2 (16.3 Mha) for the time period 1997-2004. L3JRC reports an annual area burned over South America (36.8 Mha) for the time period 2001-2004, which overlays with the lower range of the simulations (28-80 Mha). Ito and Penner (2004) report for South and Central America for the year 2000 a burned area of 12.3 Mha based on GBA2000 and ATSR fire count data. GLOBSCAR and GBA2000 estimates are 13.8 and 11.9 Mha for South America (Kasischke and Penner, 2004).
There were discrepancies between the model and satellite observations in other regions, but the large differences between the satellite-based estimates precluded an effective model evaluation in these regions. For example the model estimates for temperate North America were between 15 and 21 Mha area burned, compared with GFEDv2 estimates of 2.5 Mha and L3JRC estimates of 20 Mha. For Canada the model mean estimates ranged between 1 and 4 Mha for the 1959 to 1997 period. This was generally consistent with the mean burned area of 1.8 Mha reported in the large fire database (LFDB, Stocks et al., 2003). The model estimated burned area in boreal Asia between 1.5 and 6.6 Mha, while the satellite-based observations are higher but with large uncertainty levels (GFEDv2: 9.0 Mha, L3JRC: 42.1 Mha). Estimates reported in the literature for Russia, in which about two thirds of the world's boreal forests lie, range between 5.3 and 13.1 Mha (Soja et al., 2004, and references therein). Chang and Song (2009) found that the L3JRC product significantly overestimates the burned area in the northern high latitudes when compared with ground-based measurements and other satellite data. They related this overestimation to 
Table 3. Annual mean carbon in the above ground vegetation pools (deadstems, livestems, leaves, coarse woody debris and litter), annual burned area, and the ratio between annual carbon loss and burned area in steady state for the different simulations.

\begin{tabular}{llll}
\hline & above veg. & $\begin{array}{l}\text { annual } \\
\text { burned area }\end{array}$ & $\begin{array}{l}\text { annual carbon emission/ } \\
\text { burned area }\end{array}$ \\
\hline simulation & {$[\mathrm{Pg} \mathrm{C}]$} & {$[$ Mha/year] } & [Tg C/Mha] \\
\hline T-FULL & 722 & 136 & 16.3 \\
AB-FULL & 579 & 300 & 8.5 \\
AB-HI & 649 & 194 & 9.4 \\
AB-HI-FS & 659 & 182 & 9.8 \\
\hline
\end{tabular}

excessive detection of burned area during the period outside the fire season.

Of all the simulations, T-FULL produced the smallest annual area burned globally. A higher annual area burned was simulated in the AB-FULL simulation. The best spatial correlation between simulation and GFEDv2 as well as L3JRC was found for the AB-HI-FS simulation (0.52 and 0.53 , respectively). Taking into account human ignition and fire suppression explicitly as a function of population density (AB-HI-FS), improved the simulated annual area burned over densely populated regions such as India, Europe and the East coast of the USA in comparison to GFEDv2 and L3JRC. When only human ignition was considered (AB-HI) the spatial correlation coefficient was lower $(0.33$ and 0.34 , respectively). The impact of fire suppression and human ignition on the simulated burned area will be further discussed in Sect. 5.1.2.

Next we assessed the modeled fire emissions against available observations. The global distribution of simulated annual fire carbon emissions had a similar spatial pattern as estimates from GFEDv2 (van der Werf et al., 2006), GICC (Mieville et al., 2010) and RETRO (Schultz et al., 2008), although discrepancies are visible in several regions (Fig. 3).

The simulated global (wildfire and deforestation) fire carbon emissions were between 2.0 and $2.4 \mathrm{Pg}$ C/year for the period 1997-2004. For the same period GFEDv2 and GICC report 2.3 and $2.7 \mathrm{Pg}$ C/year, respectively. For the period 1960 to 2000 fire emissions from RETRO are 2.0 Pg C/year. During the same period, the simulations ranged between 1.7$2.2 \mathrm{Pg}$ C/year. This suggests that the models yielded reasonable global estimates of carbon emissions over this time period. Similar to the area burned, the best spatial correlation between simulated fire carbon emissions and fire products was found for the AB-HI-FS simulation (Fig. 4).

While we found a large range of annual burned area in our different simulations, the total global carbon emissions were relatively similar. This non-linear relationship between burned area and fire carbon emissions was partly explained by different aboveground vegetation pools in steady state for the different simulations (Table 3). The different annual burned area simulated with the various model configurations had a large effect on the modeled carbon stock at steady state. A simulation with high annual area burned (e.g. AB-FULL) had relatively low aboveground biomass carbon pools at steady state and thus lower fuel loads and carbon emissions per unit area burned. In contrast, a simulation with a low annual area burned (e.g. T-FULL) had relatively high aboveground biomass carbon pools at steady state and thus high rates of fire emissions per unit of burned area. In addition, different assumptions about fire-induced mortality and combustion completeness in the two different fire algorithms applied here (see Appendix A3) led to different levels of fuel consumption. Also, different distributions of burned area contribute to different levels of global emissions because of the decoupling of burned area and emissions that occurs at a global scale (van der Werf et al., 2006).

Similar to the simulated area burned, modeled fire carbon emissions were too low over the African continent (738 to $1099 \mathrm{Tg}$ C/year; GFED: $1190 \mathrm{Tg}$ C/year, GICC: $1256 \mathrm{Tg}$ C/year) and too high over South America (711 to $908 \mathrm{Tg}$ C/year, GFED: 326 Tg C/year, GICC: $502 \mathrm{Tg}$ C/year). For Africa Table 2 compares the simulated values for the period 2001 to 2004 with GFEDv2 and values given in Lehsten et al. (2009). Lehsten et al. (2009) utilized a bias corrected L3JRC area burned product for Africa to simulate fire carbon emissions within the LPJ-GUESS model (Smith et al., 2001) in a similar approach as described by van der Werf et al. (2006). Both area burned and fire carbon emissions are higher in Northern Hemisphere Africa compared to Southern Hemisphere Africa in GFEDv2, in contrast with results from Lehsten et al. (2009) that show higher levels of burned area and emissions in Southern Hemisphere Africa. The ratio between annual fire carbon emissions and area burned is $7.2 \mathrm{Tg}$ C/Mha (NHAF) and $4.5 \mathrm{Tg}$ C/Mha (SHAF) for GFEDv2, which is higher than in Lehsten et al. (2009) (4.1 and 3.2 Tg C/Mha, respectively). CLM-CN simulations had significantly higher ratios. As a result, the simulated fire carbon emissions were comparable or even exceeded the Lehsten et al. (2009) values, even though the annual area burned was simulated significantly lower.

Deforestation fires were between 141 (AB-FULL) and 204 (T-FULL) Tg C/year, or approximately $6-9 \%$ of global fire emissions, during the 1990s. This was about $34-42 \%$ of the total conversion flux related to land use change. In our model the importance of fire in the conversion process depended on climate-sensitive fire probabilities defined in Appendix A5. As a consequence, larger contributions were simulated in regions with relatively high fire probabilities such as Northern Hemisphere Africa ( $70 \%)$ and lower contributions were simulated in regions with relatively low fire probabilities such as Europe ( $30 \%)$. 


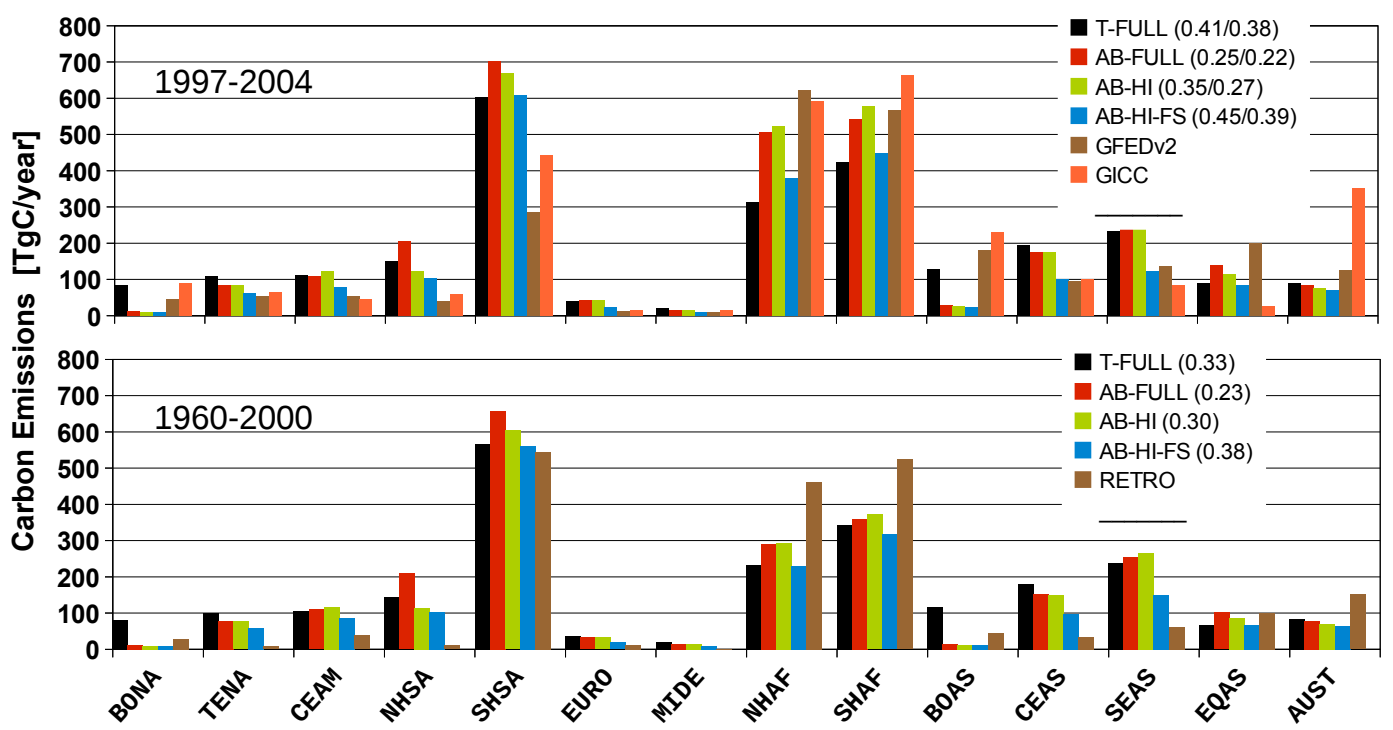

Fig. 4. Annual mean total (wildfire plus deforestation) fire carbon emissions in [Tg C/year] for different regions compared to GFEDv2 (van der Werf et al., 2006), GICC (Mieville et al., 2010), and RETRO (Schultz et al., 2008). The model simulations are averaged over the corresponding observational period (1997-2004 or 1960-2000, respectively). The number in brackets denote global spatial correlation coefficients between simulations and fire products (for the upper panel the first numbers refers to GFEDv2 and the second to GICC). Regions are defined in Fig. A3.
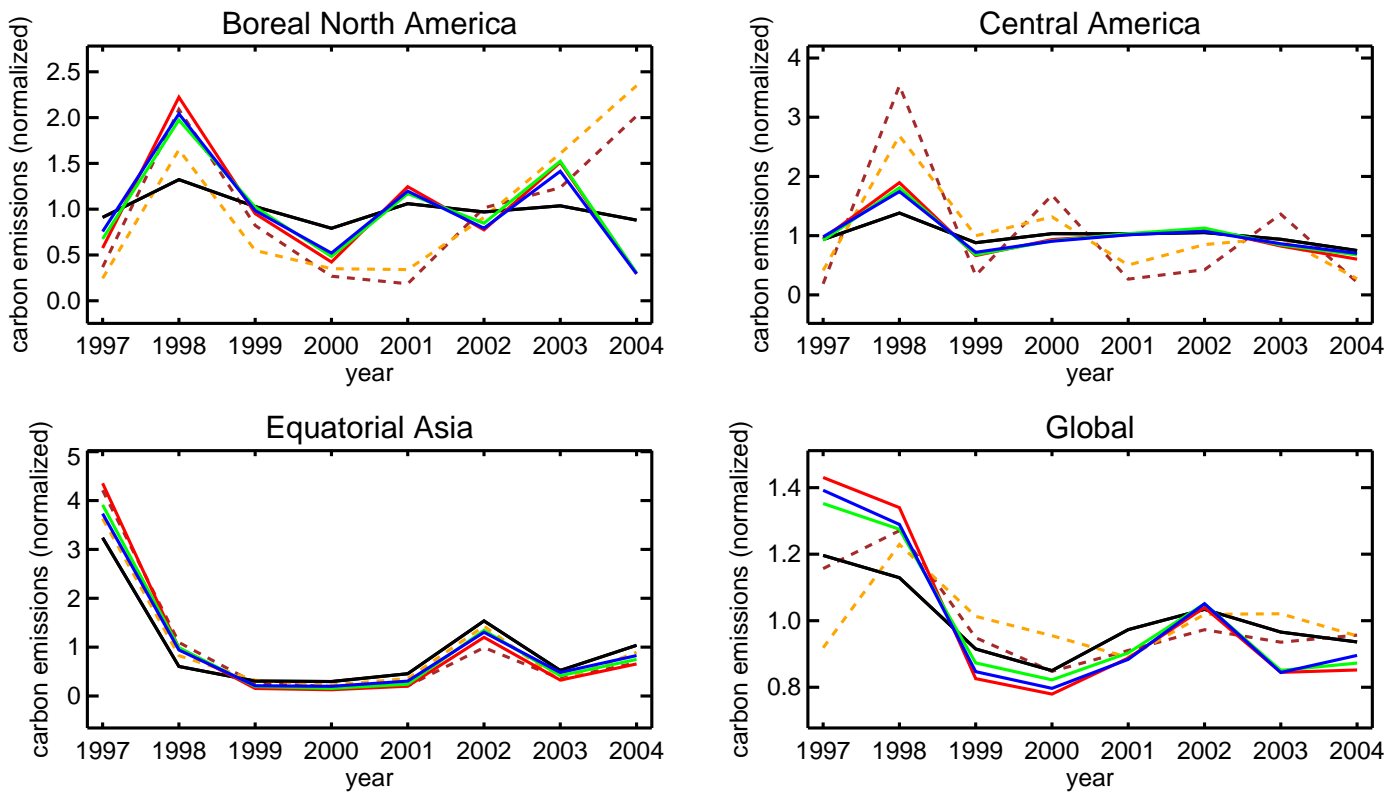

Fig. 5. Annual mean total (wildfire and deforestation) fire carbon emissions normalized by the mean for 1997-2004 for regions characterized by a high interannual variability reported in the satellite-based products and globally. Solid lines represent model simulations: black: TFULL, red: AB-FULL, green: AB-HI; blue: AB-HI-FS. Dashed lines are observations: brown: GFEDv2 (van der Werf et al., 2006); orange: GICC (Mieville et al., 2010). Correlation coefficients for the interannual variability for different regions are given in Table 4.

\subsection{Interannual and seasonal variability}

Figure 5 shows the interannual variability in total (wildfire and deforestation) fire carbon emissions as simulated be- tween 1997 and 2004 compared to estimates reported by GFEDv2 (van der Werf et al., 2006) and GICC (Mieville et al., 2010) for selected world regions, that are characterized by a high interannual variability (Table 4 ). Correlations 
Table 4. Correlation coefficient for the interannual variability (1997-2004) between model simulations and GFEDv2 (van der Werf et al., 2006) and GICC (Mieville et al., 2010) for total (wildfire and deforestation) fire carbon emissions, relative standard deviation (relative sdev) of monthly fire carbon emissions for GFEDv2 or GICC, and the interannual correlation (correlation) between GFEDv2 and GICC. Non significant correlations (confidence level below 90\%) are printed in cursive characters. Regions are defined in Fig. A3.

\begin{tabular}{|c|c|c|c|c|c|c|c|c|c|c|c|}
\hline \multirow[b]{2}{*}{ region } & \multicolumn{8}{|c|}{ Correlation - interannual variability } & \multicolumn{2}{|c|}{ relative sdev } & $\begin{array}{l}\text { correlation } \\
\text { tions }\end{array}$ \\
\hline & GFEDv2 & GICC & GFEDv2 & GICC & GFEDv2 & GICC & GFEDv2 & GICC & GFEDv2 & GICC & GFEDv2/GICC \\
\hline BONA & 0.47 & 0.26 & 0.37 & 0.21 & 0.32 & 0.16 & 0.30 & 0.12 & 0.75 & 0.78 & 0.93 \\
\hline TENA & 0.94 & 0.38 & 0.94 & 0.66 & 0.94 & 0.64 & 0.86 & 0.69 & 0.37 & 0.45 & 0.56 \\
\hline CEAM & 0.83 & 0.87 & 0.81 & 0.83 & 0.79 & 0.82 & 0.80 & 0.82 & 1.17 & 0.76 & 0.95 \\
\hline EURO & 0.48 & 0.42 & 0.74 & 0.68 & 0.73 & 0.65 & 0.80 & 0.68 & 0.37 & 0.35 & 0.86 \\
\hline MIDE & -0.03 & -0.25 & 0.36 & 0.24 & 0.38 & 0.28 & 0.42 & 0.15 & 0.57 & 0.39 & 0.80 \\
\hline NHAF & 0.46 & 0.25 & 0.39 & 0.18 & 0.30 & 0.14 & 0.24 & 0.17 & 0.12 & 0.28 & -0.02 \\
\hline SHAF & 0.36 & 0.56 & 0.01 & 0.30 & -0.12 & 0.22 & -0.01 & 0.23 & 0.12 & 0.15 & 0.83 \\
\hline BOAS & 0.40 & 0.36 & 0.29 & 0.36 & 0.31 & 0.38 & 0.40 & 0.45 & 0.70 & 0.70 & 0.81 \\
\hline GLOB & 0.88 & 0.29 & 0.92 & 0.37 & 0.91 & 0.37 & 0.91 & 0.35 & 0.14 & 0.10 & 0.64 \\
\hline
\end{tabular}

between simulations and GFEDv2 and GICC for all world regions are listed in Table 4.

Considerable interannual variation was observed in regions influenced by ENSO. Here the simulations captured the enhanced burned area and fire carbon emissions associated with El Niño induced drought conditions. For example for equatorial Asia enhanced fire carbon emissions were simulated in 1997 and to a lesser extent in 2002 in accordance with GFEDv2 and GICC estimates (with correlations of $0.95-1.00)$. Another peak in emissions occurred in 1982/1983 which was consistent with observations (Goldammer and Seibert, 1990; Schultz et al., 2008, data not shown). In Central America fire carbon emissions were highest during 1998 due to ENSO-induced drought that resulted in catastrophic burning events in the tropical forest of Southern Mexico and Central America from April to June 1998 (Kreidenweis et al., 2001). The models did a poorer job in reproducing the variability in boreal regions. For example, the models predicted higher than average emissions in boreal North America during 1998, matching observations (Kasischke and Bruhwiler, 2003), but missed the large burning event in 2004.

The simulation T-FULL underestimated interannual variability and had a lower correlation with GFEDv2 as well as GICC in many regions, including boreal North America, boreal Asia and Europe. Better results were obtained with the Arora and Boer (2005) based algorithm (simulations AB-
FULL, AB-HI, and AB-HI-FS). The explicit treatment of human ignition and fire suppression had only a small impact on the interannual variability between 1997 and 2004, which was mainly controled by interannual changes in soil moisture levels.

The timing of maximum monthly total (wildfire and deforestation) fire carbon emissions is shown in Fig. 6 compared to values reported in GFEDv2 (van der Werf et al., 2006), GICC (Mieville et al., 2010) and RETRO (Schultz et al., 2008). The simulated peaks in monthly mean total carbon emissions occurred in the northern high latitude regions in July and August in agreement with the satellite-based fire products. For the western US the model using the Arora and Boer (2005) algorithm had highest emissions during July and August. This was consistent with results based on a comprehensive data compilation of observed burned area (Westerling et al., 2003). In contrast, peak emissions occured later in the year (during September and October) when we used the Thonicke et al. (2001) fire algorithm. For Central America and Southeast Asia the simulations had maximum monthly values around March-April which also corresponded to the satellite-based fire products. For the African continent, emissions from high fire regions of the Northern Hemisphere $(0$ $10^{\circ} \mathrm{N}$ ) had a maximum in February-March. Here GFEDv2 and RETRO show an earlier peak around December-January, whereas the ATSR-based GICC product peaks mainly around February. An analysis of the individual driving factors used 
in the Arora and Boer (2005) algorithm (moisture, biomass and ignition probability) revealed that the seasonality in the simulated fire carbon emissions was largely controlled by the moisture probability ( $P_{\mathrm{m}}$, see also Eq. A7, not shown).

\section{20th century trends of fire carbon emissions}

We performed a set of sensitivity experiments to disentangle the importance of individual external forcing factors: climate, population density, land use change, and wood harvest. Before we present the long-term trends in Sect. 5.2 a more detailed analysis of the sensitivity experiments is given in the following Sect. 5.1.

\subsection{Sensitivity to external forcing}

The sensitivity studies were solely performed with CLM-CN using the fire algorithm based on Arora and Boer (2005), because this version of the model had the best agreement with contemporary satellite-based burned area estimates. The fire-carbon system in the model was highly non-linear and therefore the individual sensitivities we present here are not additive. Also, we did not perform sensitivity experiments to evaluate the impact of changing $\mathrm{CO}_{2}$ concentration or nitrogen deposition on fire carbon emissions.

\subsubsection{Climate}

To demonstrate the sensitivity of simulated burned area and total (wildfire and deforestation) fire carbon emissions to changes in climate we performed one simulation (AB-CLIM) in which CLM-CN was forced for the years 1973-2004 with the NCEP-NCAR 25 year repeat cycle (1942-1972). This simulation served as a control simulation for the ABFULL simulation, which was forced from 1973 onwards with NCEP-NCAR reanalysis data from 1973 to 2004.

Figure 7 shows the simulated differences averaged over the period 1973-1997 in annual burned area and fire emissions together with the changes in the driving factors, precipitation and temperature, as well as with the biomass probability and moisture probability as used in the Arora and Boer (2005) fire algorithm $\left(P_{\mathrm{b}}\right.$ and $P_{\mathrm{m}}$, see Eqs. A6 and A7, respectively). Land surface temperatures averaged over 19731997 were higher than the 1948-1972 mean in most regions. The global annual mean land surface temperature increased by $0.3^{\circ} \mathrm{C}$. Precipitation changes were much more heterogeneous, with large decreases in precipitation over Central Africa and Southeast Asia and increases over the USA and parts of South America. Annual burned area responded to the changes in climate with the largest increase occurring over Central Africa and parts of Southern Europe and decreases occurring in South America, temperate North America and Southeast Asia. Global annual mean burned area increased by 4 Mha $(\sim 2 \%)$, and total fire carbon emissions by less than $1 \%$. Changes in emissions were similar to the area burned response pattern. Annual burned area increased over Central Africa and Southern Europe as a direct response to decreases in precipitation and an enhanced probability of burning based on fuel moisture levels. Increases in soil moisture led to a decrease in the burned area in South America and in the eastern US. However, small regions along the US West Coast had a higher annual burned area despite increases in soil moisture. This increase in burned area was explained by an increase in biomass available for burning.

\subsubsection{Population density}

Besides lightning, humans constitute an important ignition source (Robin et al., 2006), but also actively suppress fires in more densely populated areas in which high property values are typically at risk (Stocks et al., 2003; Theobald and Romme, 2007). Human ignition as well as active fire suppression largely depend on cultural, economic, and other factors. The dynamics of these interactions with respect to wildland fire are difficult to quantify and predict at regional to global scales (Bowman et al., 2009; Guyette et al., 2002). In this study we made an attempt to parametrize the human ignition and fire suppression probabilities as a function of population density. Details on our approach can be found in the Appendix A4.

Figure 8a shows the difference in total (wildfire and deforestation) fire carbon emissions caused by changing population density from 1850 onwards together with the population density (Fig. 8b) for important source regions (Africa, South America, equatorial Asia) and globally. When we did not account for fire suppression, increases in population density caused an increase in global fire emissions by approximately $30 \%$ in the 1990s. All world regions showed an increase, which was most pronounced in Southern Hemisphere South America (100\%) and equatorial Asia (70\%). Little impact was observed for Europe (8\%) or boreal Asia (5\%).

In contrast, including fire suppression caused almost no change in global fire emissions, but did change regional distributions. Regions such as Europe, Central Asia, Southeast Asia and Middle East had strong decreases in fire emissions $(-30,-31,-40,-23 \%$ in the 1990 s, respectively) as a result of increasing urbanization and our assumption of stronger fire suppression efforts in densely populated areas. In other regions with lower population densities, increases in population increased the probability of ignitions and fire carbon emissions, including, for example in Southern Hemisphere South America, boreal North America and Australia $(+15,+10,+20 \%$ in the 1990 s, respectively). Overall this led to a better agreement between the spatial pattern of emissions in the model and the satellite-based fire products as compared to the simulations that assumed a constant human ignition probability (AB-FULL) or only accounted for human ignition as a function of population density and not fire suppression (AB-HI), as discussed in Sect. 4.1 and Fig. 4. 
T-FULL

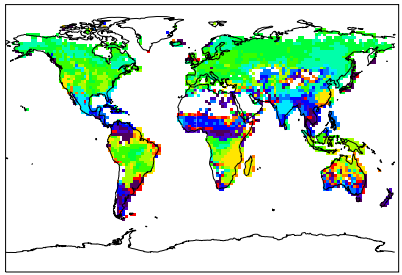

T-FULL

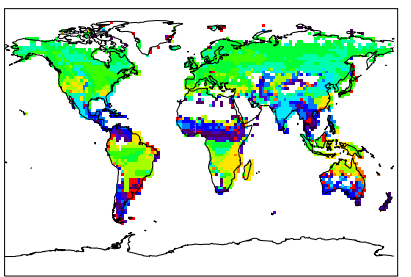

AB-HI-FS

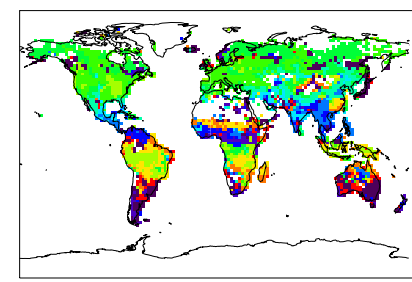

AB-HI-FS

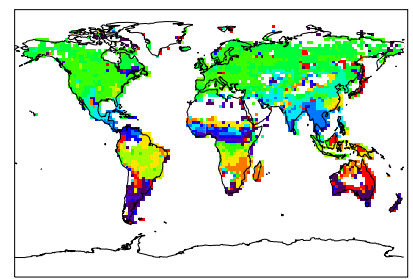

GFEDv2
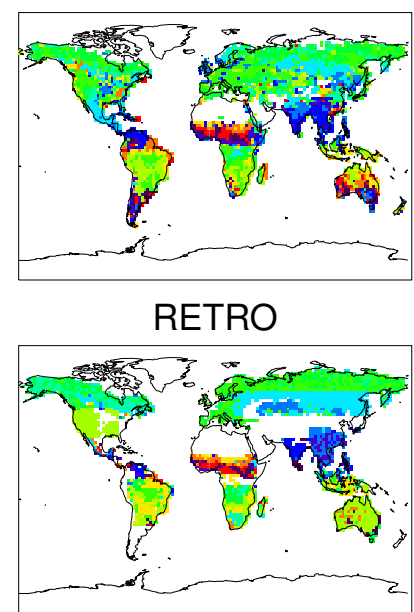

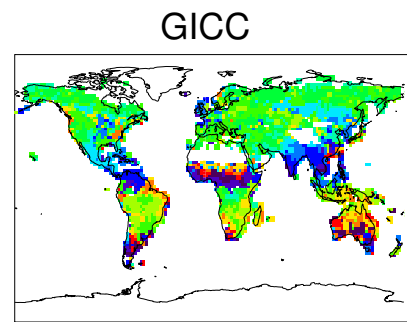

JAN FEB MARAPR MAY JUN JUL AUG SEP OCTNOVDEC

Fig. 6. Month of maximum total (wildfire plus deforestation) fire carbon emissions for the different simulations compared to different fire products: GFEDv2 (van der Werf et al., 2006), GICC (Mieville et al., 2010) and RETRO (Schultz et al., 2008). The model simulations are averaged over the corresponding observational periods (GFEDv2, GICC: 1997-2004; RETRO: 1960-2000).
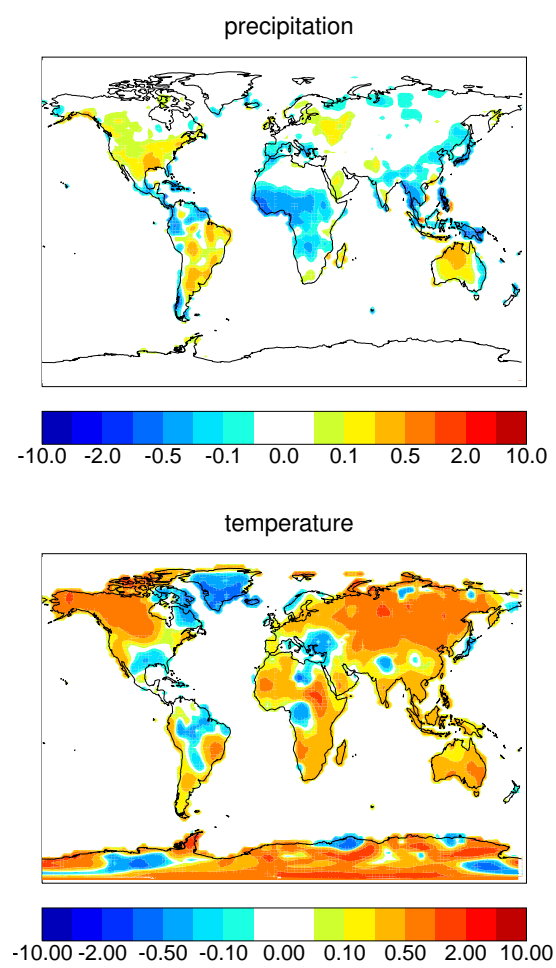
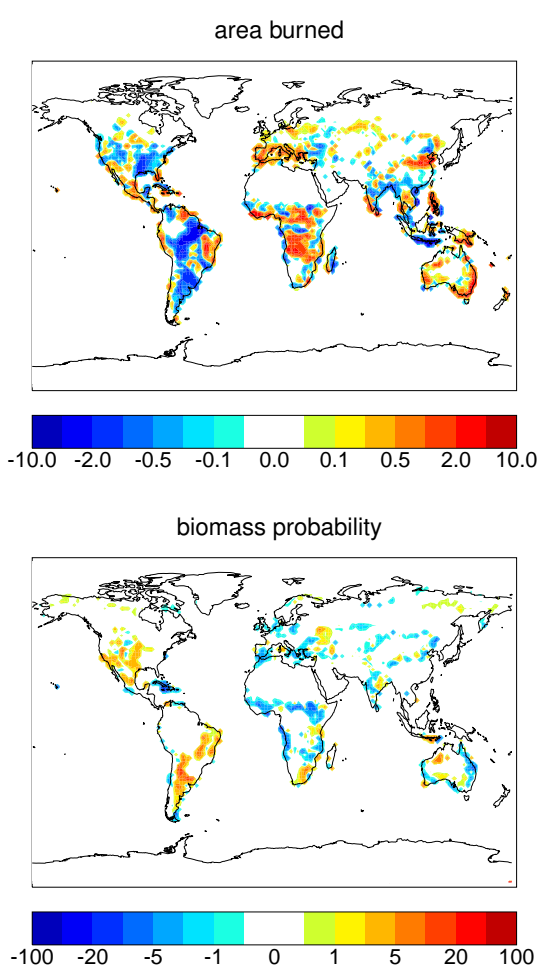
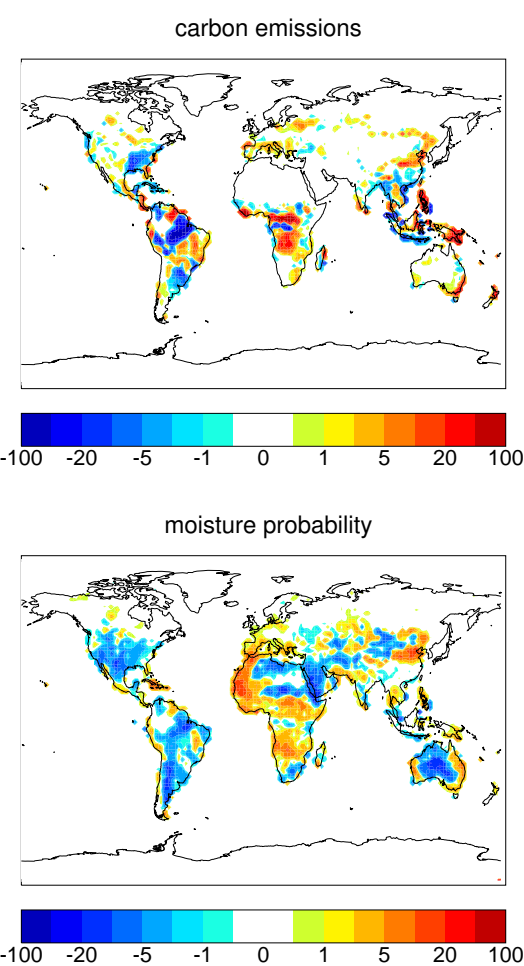

Fig. 7. Difference between simulation AB-FULL and AB-CLIM in annual mean temperature $[\mathrm{K}]$, annual mean precipitation [mm/d], annual total area burned [\% of grid box], annual mean carbon emissions $\left[\mathrm{g} \mathrm{C} / \mathrm{m}^{2} /\right.$ year] and biomass and moisture probability [ $\left.\times 100\right]$ as defined in Sect. A2 averaged over the period 1973-1997. 

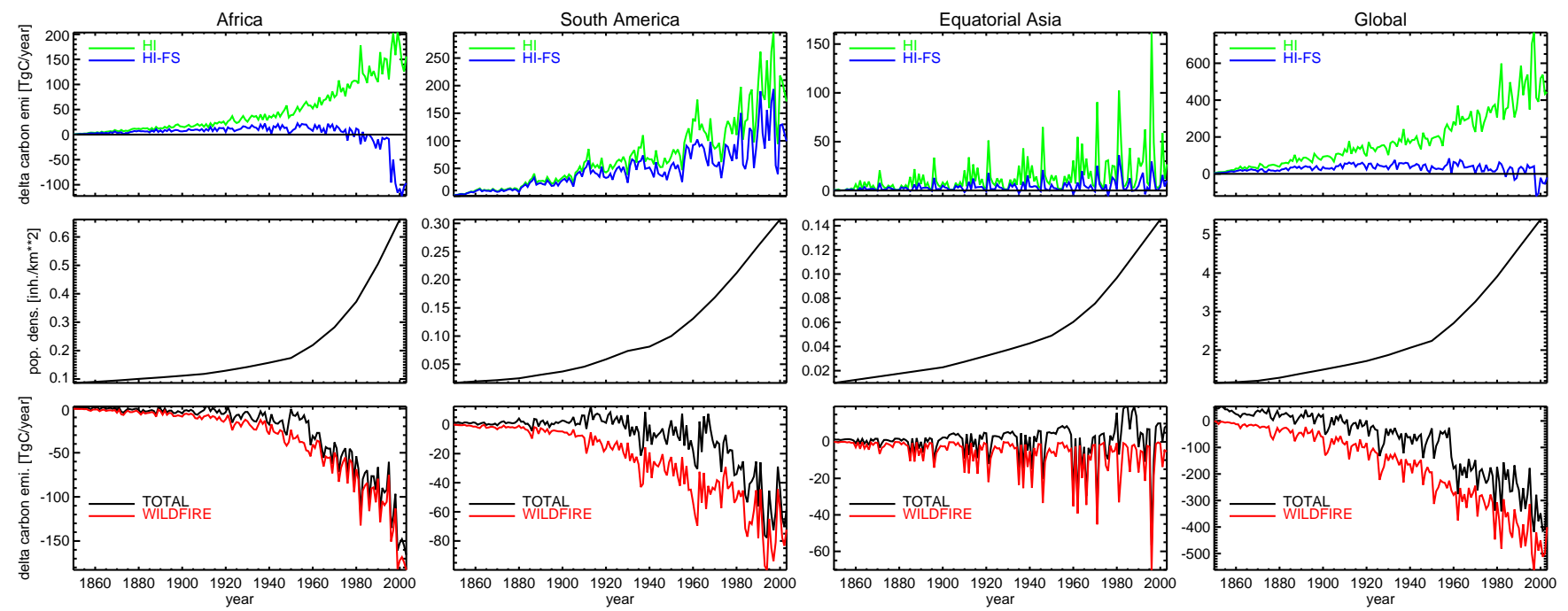

Fig. 8. Sensitivity to changes in population density and land use change and wood harvest for selected regions and globally. (A) Annual mean change in carbon emission from total fires (natural and deforestation) caused by changes in population density in the case of only human ignition is considered (green line, AB-HI - AB-HI-PI) and human ignition and fire suppression considered (blue line, AB-HI-FS AB-HI-FS-PI) in [Tg C/year]; (B) population density [inhabitants $/ \mathrm{km}^{2}$ ]; (C) change in total (wildfire and deforestation) fire carbon emissions (black) and wildfire fire carbon emissions (red) caused by land use change and wood harvest in [Tg C/year] (AB-FULL - AB-LUC).

\subsubsection{Land use change and wood harvest}

Land use change and wood harvest impact fire carbon emissions by introducing a fire source (deforestation fires, which are frequently used to eliminate biomass in preparation for agricultural use) and by removing biomass available for burning. Thus, the net effect of land use activities can increase or decrease fire emissions.

The globally averaged trends in fire emissions from deforestation showed a large increase over the 20th century (Fig. 9). During the 1990s, the regions that contributed the most to deforestation fire emissions were Asia, Africa and South America. Maximum deforestation fires for the 20th century occurred in the model during the 1950s and were driven by large land cover changes globally. At the beginning of the 20th century North America, Asia, and Europe were the main contributors to the global deforestation fire flux and Africa and South America were only of minor importance.

Globally the deforestation fire carbon loss in the 1990s was $141 \mathrm{Tg}$ C/year. However, adding in deforestation and wood harvest reduced the carbon loss from wildfires by $433 \mathrm{Tg}$ C/year ( $-16 \%$, Fig. 8c). This decrease can be explained by a globally reduced aboveground biomass pool caused by land use change and wood harvest. Global total (wildfire and deforestation) fire emissions were consequently reduced by $292 \mathrm{Tg}$ C/year (-11\%, Fig. 8c).

Regionally, the reduction in total carbon fire emissions was strongest in boreal North America (-21\% in the 1960s), temperate North America ( $-30 \%$ in the 1980 s), Europe $(-25 \%$ in the $1990 \mathrm{~s})$ and Southeast Asia $(-25 \%$ in the 1990s). A few regions and time periods had significantly enhanced total fire carbon emissions, i.e. deforestation fire carbon emissions more than compensated for any decreases in wildfire emissions caused by reduced biomass availability. These regions include: boreal North America (1850s to 1920s: 11-44\%), temperate North America (1850s to 1890s: 6-15\%), Europe (1850s to 1910: 4-11\%), boreal Asia (1850s to 1990s: 8-100\%), central East Asia (1850s to 1980s: 2-27\%) and equatorial Asia (1990s: 13\%).

Land use change and wood harvest overall led to a $24 \mathrm{Pg} \mathrm{C}$ reduction in carbon emitted by wildfires between 1850 and 2000 , which was partly compensated by deforestation fire carbon emissions of $14 \mathrm{PgC}$. Wood harvest accumulated $75 \mathrm{PgC}$ within the same time period, with this carbon ultimately redistributed in wood and paper products. $21 \mathrm{PgC}$ were gained by the wood and paper product pools through land use change and $42 \mathrm{PgC}$ were lost to the atmosphere by direct conversion.

Overall land use change activities caused a net terrestrial carbon source of $1.2 \mathrm{Pg}$ C/year in the 1990s. This flux is in the range of current estimates ranging between $-0.6 \mathrm{Pg}$ C/year and 1.8 Pg C/year (Ito et al., 2008) and similar to a recent estimate of 1.1 to $1.3 \mathrm{Pg}$ C/year by Shevliakova et al. (2009). During 2000-2004 this source decreased to $0.85 \mathrm{Pg} \mathrm{C} /$ year. Deforestation fires contributed to approximately $11 \%$ of this net carbon source.

\subsection{Trends in carbon emissions}

Mieville et al. (2010) use historical burned area estimates by Mouillot et al. (2006) to scale contemporary satellite-based 


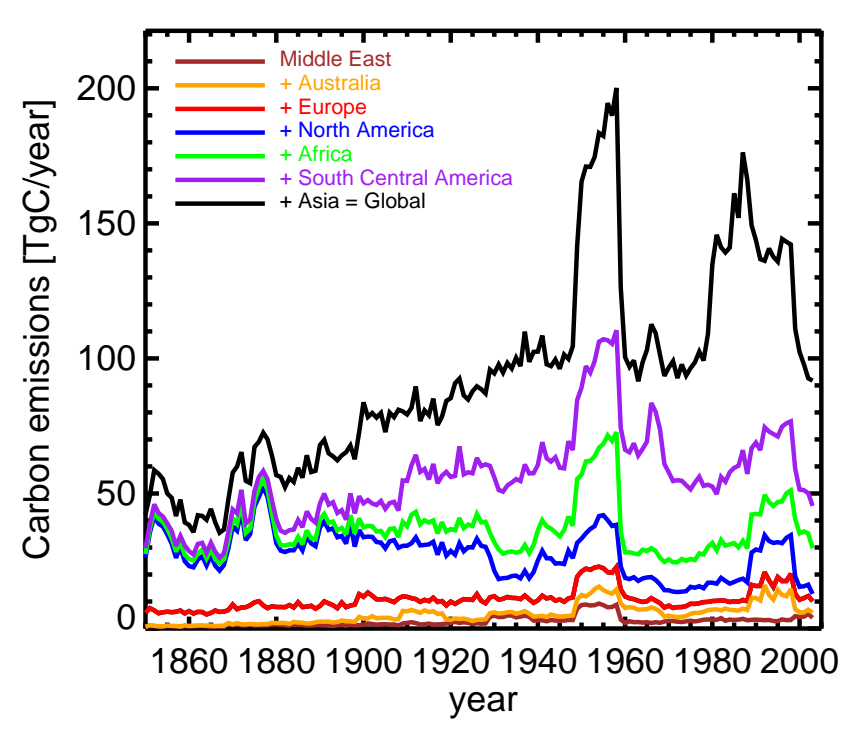

Fig. 9. Annual mean fire emissions from deforestation [Tg C/year] as simulated in simulation AB-FULL. The contribution of each region is stacked onto the region plotted below, so that the black line represents the global sum of fire emissions from deforestation.

observations back in time (GICChist). Mouillot et al. (2006) note that for the fire history of the 20th century the underlying data source is too sparse to support a reconstruction with high quantitative accuracy and thus they recommend using their time series to identify large-scale trends and patterns. Here we compared our simulated values against GICChist normalized to the mean state 1900-2000 in Fig. 10, which also summarizes the results from the sensitivity experiments as percentage changes in decadal mean emissions caused by the individual forcing factors (as described in Sect. 5.1).

The trend analysis of our simulation for the 20th century was limited as we only forced the model with reanalysis data corresponding to the 1948-2004 period (before 1948 the model was forced with a repeating set of 25 years of NCEP/NCAR reanalysis from 1948-1972). Changes in total fire carbon emissions before 1948 were therefore only driven by changes in the external forcing factors: population density, atmospheric $\mathrm{CO}_{2}$ concentration, nitrogen deposition, land use change, and wood harvest. During 19482004 the simulated trends were caused by the full set of external forcings including climate.

Globally we found a slight downward trend from 1900 to 1960 in agreement with GICChist, except for the simulation that assumed that human ignition increases with population density, which led to a moderate upward trend. The last three decades for all simulations were characterized by an upward trend caused by climate variations and large burning events in 1997-1998 associated with ENSO-induced drought.

GICChist shows a decreasing trend over the 20th century in boreal regions and an exponential increase in tropical forests, which the authors relate to more stringent fire sup- pression policies in boreal regions and the use of fire in deforestation in the tropical regions, respectively. Near the end of the 20th century, they find some evidence of an increase in burned area within temperate forests.

Our simulated trend was consistent with these findings for the boreal zone of North America, although our simulated increase started slightly later. In particular, land use change led to deforestation fires between 1900 and 1925 and an increase in total fire carbon emissions. Between 1950-1975, however, sustained levels of wood harvesting caused a reduction in available biomass and a corresponding decrease in total fire carbon emissions. The magnitude of the simulated decrease between 1950 and 1975 was much smaller than the one reported in GICChist. A subsequent increase in the modeled carbon emissions from 1975 to 2000 was mainly related to a combination of land use change activities and climate warming. In contrast with the $\mathrm{AB}$ simulations fire emissions from T-FULL did not change substantially in the boreal regions during the 20th century.

For South America GICChist shows an increase throughout the 20th century, which is most pronounced in the last three decades. The simulations rather showed a large decadal variability in fire carbon emissions, due to variations in the 25 year cyclic climate forcing through the 1960s, followed by a sharp decrease caused by enhanced precipitation rates in the 1970s. After the 1970s fire emissions returned to high values.

For Europe our simulations were in qualitative agreement with GICChist, but the simulated trends were smaller. The best agreement was achieved by the inclusion of fire suppression. In contrast, in Southeast Asia the inclusion of fire suppression caused a pronounced decrease in simulated total fire carbon emissions throughout the 20th century, which is not observed in GICChist.

Africa had a pronounced upward trend in total fire carbon emissions for the last decades in the 20th century in the simulations as well as in the trend reported by GICChist. In the simulations this trend can be explained by a change in climate leading to drier conditions over Northern Hemisphere Africa at the end of the 20th century.

These results are in contrast to those reported by Ito and Penner (2005). Ito and Penner (2005) constructed an inventory of biomass burning black carbon (BC) and particulate organic matter (POM) emissions for the period 1870-2000 based on a bottom up inventory for open vegetation burning scaled by a top-down estimate for the year 2000. Monthly and interannual variations were derived from TOMS aerosol index between 1979 and 2000. Prior to 1979, emissions were scaled to a $\mathrm{CH}_{4}$ emission inventory based on land use change (Stern and Kaufmann, 1996). As a result of increasing deforestation rates (Houghton et al., 1983) open vegetation burning increases between 1870 and 2000 in the Ito and Penner (2005) estimates. This is in contrast to our simulated decreasing trend in global fire carbon emissions between the 1900s and 1960s caused by strong wood harvesting 

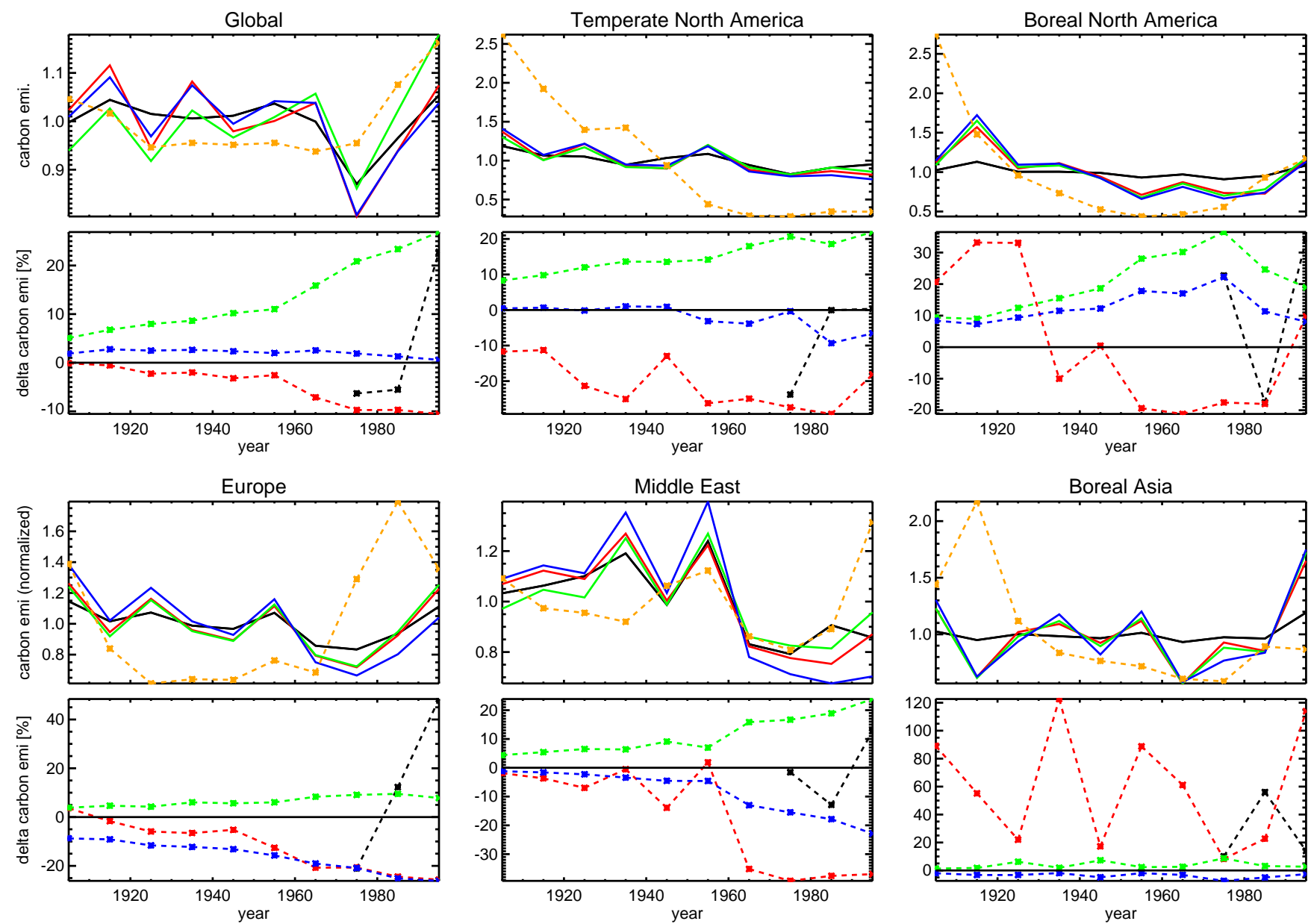

Fig. 10. Upper panels: Trend in decadal total (wildfire and deforestation) fire carbon emissions compared to decadal mean GICChist estimates (Mieville et al., 2010) for different regions from 1900 to 2000 normalized with the mean value for 1900-2000. Solid lines represent model simulations: black: T-FULL, red: AB-FULL, green: AB-HI; blue: AB-HI-FS. Dashed orange line with symbols are observations (GICChist); Lower panels: decadal mean change in total carbon loss in [\%] with respect to the respective control simulation caused by red: land use change and wood harvest, green: human ignition, blue: human ignition and fire suppression, black: climate. Note here, that the fire carbonsystem is highly non-linear and therefore the individual responses are not additive.

rates and decreases in biomass available for burning. Marlon et al. (2008) compiled sedimentary charcoal records over the last two millennia. Their analysis shows a long-term downward trend in biomass burning between 1-1750 followed by a sharp increase from 1750 to the late 19 th century and a decrease from the late 19th to mid-to-late 20th century on the global scale. They hypothesize that the long-term downward trend following 1870 can be explained by land use change and wood harvest, which they argue results in landscape fragmentation and generally less flammable landscapes in many regions. This is qualitatively consistent with our results.

Schultz et al. (2008) utilize different satellite products for contemporary fire carbon emissions estimates and an extensive literature review in combination with a numerical fire model to scale these back in time for the time period 1960
2000. In Fig. 11 we compare annual total carbon emissions from our simulations to these values. The comparison showed in general a reasonable agreement. Our simulations had a moderate upward trend in total fire carbon emissions between 1970-2000, which was in broad agreement with the RETRO time series and was mainly caused by large burning events in 1982-1983 and 1997-1998 associated with the ENSO-induced drought conditions. From 1960 to 1970 the simulations had a downward trend, whereas RETRO shows almost no trend. The simulated trends were driven mainly by changes in climate. Other external forcings such as population density, land use change and wood harvest impacted only slightly the total carbon emissions between 1960 and 2000 (cf. Fig. 8). Our simulations were qualitatively consistent with the findings from Duncan et al. (2003) that show 

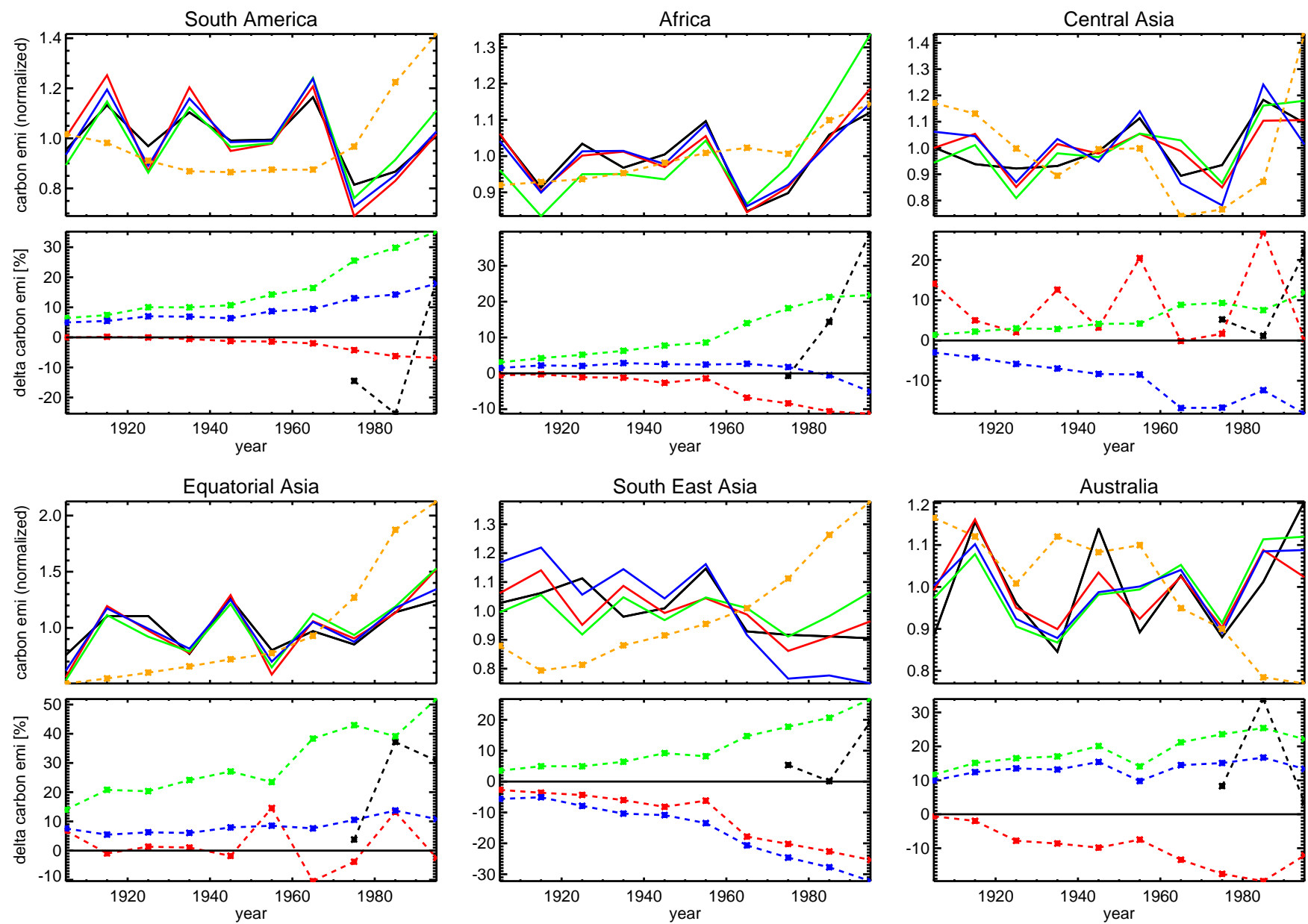

Fig. 10. Continued.

an upward trend in fire emissions between 1979 and 2000, related to large burning events in 1997-1998. The Duncan et al. (2003) estimates are based on ATSR and AVHRR for seasonal variations and TOMS aerosol index as a surrogate for interannual variability.

\section{Discussion and conclusions}

In this study we improved the representation of fire processes within the Community Land Model (CLM-CN, Thornton et al., 2007) and simulated carbon emissions from fires during the 20th century. CLM-CN originally included a prognostic treatment of fires based on the work by Thonicke et al. (2001). Here we developed a new fire algorithm based on the work by Arora and Boer (2005). Our goal was to reproduce contemporary observed burned areas and fire carbon emissions. For this purpose we extended the model by an explicit treatment of the human ignition and fire suppression as a function of population density. In addition, we introduced a parametrization of deforestation fire carbon emissions mak- ing use of land use change transition scenarios (Hurtt et al., 2006). We performed several sensitivity experiments to separate the effects of external driving factors (population density, land use change and wood harvest, and climate) on fire emissions over the last century. The results of this study provide a self-consistent emissions dataset for fire emissions of carbon dioxide, reactive gases and aerosols for the 20th century (not discussed here), which can be used in future in chemical transport and climate modeling studies.

Our model was able to capture much of the observed mean and variability in burned area and carbon emissions. Simulated global annual total fire carbon emissions ranged between 2.0 and 2.4 Pg C/year for the time period 1997 to 2004 and were within the uncertainty of satellite-based estimates. For the most part the model captured the observed patterns of fires, but we consistently overestimated annual area burned and emissions for South America and underestimated these quantities for Africa when we compared our simulations to a range of observations. This mismatch could be the result of several factors including an overestimation of the 


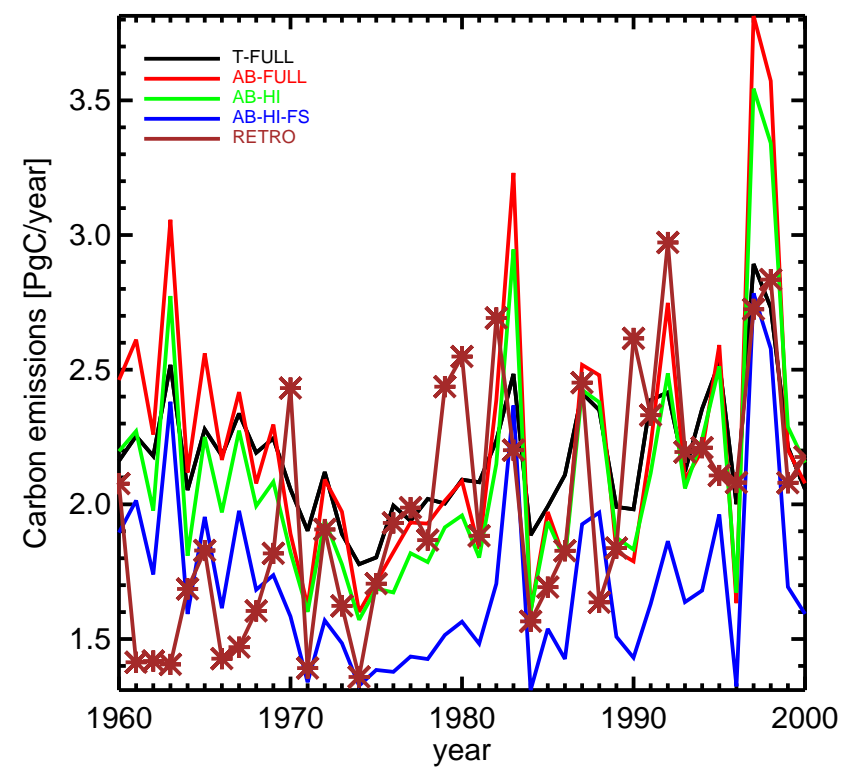

Fig. 11. Annual mean total (wildfire and deforestation) fire carbon emissions for the different simulations from 1960-2000 compared to values reported in RETRO (Schultz et al., 2008).

live aboveground biomass in the Amazon basin in CLM-CN (Randerson et al., 2009). On interannual timescales we found a reasonably good agreement between simulated fire emissions and satellite-based results. All simulations captured the large interannual variability associated with El-Niño-induced drought conditions in equatorial Asia. Our model was able to predict the timing of peak emissions in many parts of the world. However, for Central Africa our simulations tended to simulate the timing of maximum monthly emissions during February/March, lagging the observations by one to two months. The Arora and Boer (2005) fire algorithm extended by a parametrization of human ignition and fire suppression provided the best agreement with the observations in term of spatial pattern, interannual and seasonal variability and longterm trends during the 20th century.

To improve the fire model, and generally our understanding of fires in the Earth System, we require improved data on a global scale. Large discrepancies remain between the different satellite sensor products (Boschetti et al., 2004; Roy and Boschetti, 2009; Chang and Song, 2009; Giglio et al., 2010), which hampers prognostic model validation in many regions. Improved satellite fire products that include uncertainty ranges would facilitate development of improved global prognostic fire algorithms. Also, estimates of deforestation fire carbon emissions are associated with large uncertainties. In our model they depend strongly on the assumptions made in the underlying land use change scenario, wood harvesting rates and the apportionment of carbon affected by land use change into product and conversion pools. In addition, the breakdown of the conversion flux into fire and non-fire related carbon emissions using ratios that solely depend on the moisture driven fire probability, as done in this study, does not account for cultural and socio-economic factors that often control deforestation fire emissions (Morton et al., 2006; Geist, 2001). Satellite-based estimates on forest clearing (Hansen et al., 2008) combined with satellite-based fire products should improve our understanding of deforestation fires in the future and will help to further improve the deforestation fire parametrization introduced in this study. In addition, there are many important processes related to fires that are not included in the fire algorithms used in this study such as maintenance fires (van der Werf et al., 2009), seasonal changes in combustion factors due to varying fuel moisture and litter amounts (Hoffa et al., 1999), and peat fires (Page et al., 2002). Also, a more detailed analysis of the relationship between population distribution and human ignition and fire suppression is an important task to reduce uncertainties in the modeling of fires.

Using our improved model we predicted the following patterns of fire emissions during the 20th century:

- The simulations had a small global downward trend in decadal mean fire carbon emissions between 1900 and $1960(\sim-5 \%)$. This downward trend in many regions was explained by land use change and wood harvest and an associated decrease in available biomass.

- The last three decades in the 20th century were dominated by an upward trend in global total fire carbon emissions $(\sim+30 \%)$ caused by climate variations and large burning events associated with ENSO-induced drought conditions.

- Land use change activities between 1850 and 2000 released $14 \mathrm{Pg} \mathrm{C}$ from deforestation fires, but reduced carbon emissions from wildfires by $24 \mathrm{PgC}$. Thus, total (wildfire and deforestation) fire carbon emissions were reduced by $10 \mathrm{Pg} \mathrm{C}(-3 \%)$.

- The net flux of carbon to the atmosphere due to land use activities was simulated as $1.2 \mathrm{Pg}$ C/year for 1990 1999 (similar to previous estimates in Ito et al., 2008; Shevliakova et al., 2009). For 2000-2004 this source decreased to $0.85 \mathrm{Pg}$ C/year.

- Deforestation fires contributed to about 6-9\% of the total global fire carbon emissions during 1990-1999. The largest contribution from these fires (8-15\%) occurred during the 1950s due to strong land use change activities globally.

Our 20th century trends were broadly consistent with estimates based on sedimentary charcoal records (Marlon et al., 2008) and historical estimates based on published data, land use practices, qualitative reports and tree ring analysis (Mouillot et al., 2006). However, discrepancies remain on 
regional scales and further work is required to resolve these differences.

Although the model was limited in the processes considered and simplified in many aspects, it captured reasonably well the global distribution and interannual variability. The model can be introduced into an Earth System model. This will be an important step towards quantifying the role of fire in climate-carbon feedbacks.

\section{Appendix A}

\section{Fire algorithms in CLM-CN}

Two fire algorithms were implemented into CLM-CN based on the work by Thonicke et al. (2001) and Arora and Boer (2005). The fire algorithms have common elements, including that they first estimate the area burned and then carbon fluxes related to combustion and mortality. While Thonicke et al. (2001) uses an empirical relationship relating fire season length and burned area, Arora and Boer (2005) introduces a process based fire parametrization. Both algorithms and their implementation into CLM-CN are described more in detail in the following sections.

\section{A1 Fire algorithm based on Thonicke et al. (2001)}

The fire algorithm developed for the LPJ model (Sitch et al., 2003) was modified by Thornton et al. (2007) to translate from the original annual time step to the sub-daily time step used for carbon and nitrogen calculations in CLM-CN. The algorithm assumes that fire occurrence is solely a function of fuel-availability and inferred fuel moisture conditions. Ignition sources are assumed to be ubiquitous and uniform. Details on the assumptions made can be found in Thonicke et al. (2001). Here we report how the algorithm was implemented into CLM-CN.

\section{A1.1 Fire probability}

A minimum of $100 \mathrm{~g} \mathrm{C} / \mathrm{m}^{2}$ of dead fuel is required for fire occurrence. The dead fuel density in CLM-CN is the sum of the litter and coarse woody debris pool. In order to allow fire occurrence and fire spread the fuel moisture also has to be below a certain threshold (moisture of extinction, $m_{\mathrm{e}}$ ). The moisture of extinction is assumed to be 0.3 for woody biomass and 0.2 for herbaceous biomass. As a substitute for fuel moisture, which is not simulated in CLM-CN, the soil moisture $(m)$ as a fraction of the plant-available volumetric water content of the top $5 \mathrm{~cm}$ of the soil column is used similar to Thonicke et al. (2001). In addition to fuel availability and fuel moisture constraints, fire occurrence is controlled by surface temperatures, which have to be above freezing.
The probability of fire occurrence at least once a day is given as:

$\mathrm{fp}= \begin{cases}\exp \left(-\pi *\left(\frac{m}{m_{\mathrm{e}}}\right)^{2}\right) & \text { if fuel density }>100 \mathrm{~g} \mathrm{C} / \mathrm{m}^{2}, \\ & m<m_{\mathrm{e}}, \\ & \text { and } T>273.15 \mathrm{~K}, \\ & \text { otherwise. }\end{cases}$

\section{A1.2 Area burned}

In Thonicke et al. (2001) the daily fire occurrence probability is used to estimate the annual mean fire season length ( $N$, [days/yr]), by summing fp over a year, with $N$ updated once per year. This approach is modified in CLM-CN. $N$ is updated every model timestep using an e-folding approximation for the annual sum of fp. This translates the annual time step from Thonicke et al. (2001) into the sub-daily model timestep of CLM-CN to account for seasonal variations in fire occurrence.

The e-folding approximation is done as follows: The $n$ time step running mean of a variable $x$ at the model time step $i\left(\bar{x}_{i}\right)$ was approximated by the following weighted sum:

$\bar{x}_{i}=\bar{x}_{i-1} \frac{n-1}{n}+x_{i} \frac{1}{n}$

For an annual running mean the number of e-folding timesteps $(n)$ was set to the number of model time steps in a year.

Following Thonicke et al. (2001) the annual fractional area burned ( $f_{\text {annual }}$, [fraction burned/yr]) was derived from the one-year e-folding mean fire probability $\left(\overline{\mathrm{fp}}_{i}\right)$ at each model timestep $i$ :

$$
f_{\text {annual }}=\overline{\mathrm{fp}}_{i} \cdot \exp \left(\frac{s-1}{0.45(s-1)^{3}+2.83(s-1)^{2}+2.91(s-1)+1.04}\right)
$$

with $s=N / 365$. The fractional area burned per time step in seconds $\Delta t\left(f_{\Delta t}\right)$ is given as:

$f_{\Delta t}= \begin{cases}\frac{\mathrm{fp}_{i}}{N} f_{\text {annual }} \frac{\Delta t}{86400} & \text { for } N=365 \cdot \overline{\mathrm{fp}}_{i} \neq 0, \\ 0 & \text { for } N=365 \cdot \overline{\mathrm{fp}}_{i}=0 .\end{cases}$

\section{A2 Fire algorithm based on Arora and Boer (2005)}

The fire algorithm developed for the CTEM model (Verseghy et al., 1993) is implemented into CLM-CN. Details on the algorithm are given in Arora and Boer (2005). Here we describe how the algorithm was implemented into CLM-CN.

\section{A2.1 Fire probability}

Total probability of fire occurrence is estimated as the product of three scalars that represent control from biomass, moisture and ignition:

$P=P_{\mathrm{b}} P_{\mathrm{m}} P_{\mathrm{i}}$ 
where $P_{\mathrm{b}}$ takes into account that a certain biomass has to be available for burning and is represented as:

$P_{\mathrm{b}}=\max \left[0, \min \left(1,\left(F-F_{1}\right) /\left(F_{\mathrm{u}}-F_{1}\right)\right)\right]$

with $F_{1}=200 \mathrm{~g} \mathrm{C} / \mathrm{m}^{2}$ and $F_{\mathrm{u}}=1000 \mathrm{~g} \mathrm{C} / \mathrm{m}^{2}$ and $F$ is the aboveground biomass available for burning (combined leaf, stem, litter and coarse woody debris (cwd) pools).

$P_{\mathrm{m}}$ is the fire probability conditioned on the moisture $(\mathrm{m})$ and expressed as follows:

$P_{\mathrm{m}}=1-\tanh \left(1.75 \cdot m / m_{\mathrm{e}}\right)^{2}$

$m_{\mathrm{e}}$ is the moisture of extinction, defined here as 0.35 independent of fuel type. We defined $m$ in the same way as for the Thonicke et al. (2001) algorithm as a fraction of plantavailable volumetric water content in the top $5 \mathrm{~cm}$ of the soil as a surrogate for fuel moisture content.

$P_{\mathrm{i}}$ represents the probability of an ignition source, which can be either human or natural (lightning). Ignition due to lightning is represented using cloud to ground lightning frequency (flashes $/ \mathrm{km}^{2} / \mathrm{month}$ ) which is linearly scaled between essentially no flashes $\left(\mathrm{LF}_{\text {low }}=\right.$ 0.02 flashes $/ \mathrm{km}^{2} / \mathrm{month}$ ) and the maximum observed values $\left(\mathrm{LF}_{\mathrm{up}}=0.70\right.$ flashes $\left./ \mathrm{km}^{2} / \mathrm{month}\right)$.

$\beta_{i}=\max \left[0, \min \left(1,\left(\mathrm{LF}-\mathrm{LF}_{\text {low }}\right) /\left(\mathrm{LF}_{\mathrm{up}}-\mathrm{LF}_{\text {low }}\right)\right)\right]$

For the lightning frequency we used the Lightning Imaging Sensor/Optical Transient Detector product (LIS/OTD) which reports total flash rates (cloud-to-ground and intracloud flashes). We estimated the fraction of the total flash rate that can ignite a fire (cloud-to-ground flashes) by introducing a latitude dependency of the fraction of total flashes to cloud-to-ground flashes (Pierce, 1969).

The probability of the ignition by lightning is formulated as follows:

$P_{1}=\beta_{\mathrm{i}} /\left(\beta_{\mathrm{i}}+\exp \left(1.5-6 \beta_{\mathrm{i}}\right)\right)$

The total ignition potential (combination of natural ignition and human potential $\left(P_{\mathrm{h}}\right)$ ) is formulated according to:

$P_{\mathrm{i}}=P_{1}+\left(1-P_{1}\right) P_{\mathrm{h}}$

\section{A2.2 Area burned}

The area burned is assumed to form an elliptical shape around the point of ignition defined by the fire spread rates in upwind and downwind directions as well as the length-tobreath ratio of the ellipse. To be in accordance with the daily time step used in Arora and Boer (2005) we applied an efolding approximation of the daily mean following Eq. (A2). For the area burned calculations we exactly used the formulation given by Arora and Boer (2005). For completeness we report them here. For details on the parameters and assumptions applied we refer the reader to Arora and Boer (2005).
The fire spread rate in $[\mathrm{km} / \mathrm{h}]$ in downwind direction is represented as:

$u_{\mathrm{p}}=g(\mathrm{ws}) h(m) u_{\max }$

with $u_{\max }$ the maximum fire spread rate $(0.45 \mathrm{~km} / \mathrm{h})$. The dependence on the wind speed (ws) is given by

$g(\mathrm{ws})=1.0-\left(1.0-g_{0}\right) \exp \left(-\left(\mathrm{ws}^{2} / 2500\right)\right)$

In here $g_{0}$ is 0.1 and ws is the wind speed in $[\mathrm{km} / \mathrm{h}]$.

The dependence upon the moisture is represented with $h(m)$

$h(m)=\left(1-\beta_{m}\right)^{2}$

$\beta_{\mathrm{m}}=\left\{\begin{array}{lll}m / m_{\mathrm{e}} & \text { for } & m<m_{\mathrm{e}}, \\ 1 & \text { for } & m>m_{\mathrm{e}}\end{array}\right.$

The length to breath ratio is given by:

$l_{\mathrm{b}}=1+10(1-\exp (-0.017 \cdot \mathrm{ws}))$

Assuming that the downwind fire spread rate equals 0.2 the upwind fire spread rate, the total area burned in $\left[\mathrm{km}^{2}\right]$ is then given as:

$a=0.36 \cdot \pi \cdot u_{p}^{2} / l_{\mathrm{b}} \cdot t^{2}$

Assuming that the fire burns on average one day, the actual potential area burned within one day can be approximated as:

$A=a(1-q)(2-q) / q^{2}$

with $q=0.5$. The area affected in a time step is then given as the product of fire probability $(P)$, the potential area burned $(A)$ divided by the number of model timesteps within a day $(86400 / \Delta t)$

$A_{\text {burn }}=A \cdot P \cdot(\Delta t / 86400)$

This area burned $\left(A_{\text {burn }}\right)$ is according to Arora and Boer (2005) representative for $1000 \mathrm{~km}^{2}$. The fractional area burned per time step $\Delta t$ is subsequently given by:

$f_{\Delta t}=A_{\text {burn }} / 1000$.

\section{A3 Fire emission, combustion completeness and mortality}

To account for different levels of mortality associated with fire in different vegetation types and that only part of the affected biomass is combusted and released into the atmosphere, we introduced a mortality factor (mort) and a combustion completeness factor (cc) as functions of the different PFTs and fuel types considered in CLM-CN. Similar factors are defined by Arora and Boer (2005). Thonicke et al. (2001) uses a "fire resistance" factor (1-mort), which varies among different plant functional types, but does not account for the fact that biomass is only partly combusted during a fire. In CLM-CN we modified the Thonicke et al. (2001) algorithm 
Table A1. Mortality (MORT) factors for different plant functional types and fuel types after Thonicke et al. (2001) and combustion completeness (CC) factors used in CLM-CN in combination with the Thonicke et al. (2001) algorithm.

\begin{tabular}{|c|c|c|c|c|c|c|c|c|}
\hline PFT & CC Leaf & CC Stem & CC Root & CC Litter & CC CWD & MORT Leaf & MORT Stem & MORT Root \\
\hline needleleaf evergreen temperate tree & 1.0 & 0.2 & 0.2 & 1.0 & 0.2 & 0.78 & 0.78 & 0.78 \\
\hline needleleaf evergreen boreal tree & 1.0 & 0.2 & 0.2 & 1.0 & 0.2 & 0.78 & 0.78 & 0.78 \\
\hline needleleaf deciduous boreal tree & 1.0 & 0.2 & 0.2 & 1.0 & 0.2 & 0.78 & 0.78 & 0.78 \\
\hline broadleaf evergreen temperate tree & 1.0 & 0.2 & 0.2 & 1.0 & 0.2 & 0.50 & 0.50 & 0.50 \\
\hline broadleaf deciduous tropical tree & 1.0 & 0.2 & 0.2 & 1.0 & 0.2 & 0.50 & 0.50 & 0.50 \\
\hline broadleaf deciduous temperate tree & 1.0 & 0.2 & 0.2 & 1.0 & 0.2 & 0.78 & 0.78 & 0.78 \\
\hline broadleaf deciduous temperate shrub & 1.0 & 0.2 & 0.2 & 1.0 & 0.2 & 0.78 & 0.78 & 0.78 \\
\hline broadleaf deciduous boreal shrub & 1.0 & 0.2 & 0.2 & 1.0 & 0.2 & 0.78 & 0.78 & 0.78 \\
\hline c3 arctic grass & 1.0 & 0.2 & 0.2 & 1.0 & 0.2 & 1.0 & 1.0 & 1.0 \\
\hline c3 non-arctic grass & 1.0 & 0.2 & 0.2 & 1.0 & 0.2 & 1.0 & 1.0 & 1.0 \\
\hline c4 grass & 1.0 & 0.2 & 0.2 & 1.0 & 0.2 & 1.0 & 1.0 & 1.0 \\
\hline
\end{tabular}

Table A2. Combustion Completeness (CC) and Mortality (MORT) factors for different plant functional types and fuel types after Arora and Boer (2005).

\begin{tabular}{|c|c|c|c|c|c|c|c|c|}
\hline PFT & CC Leaf & CC Stem & CC Root & CC Litter & CC CWD & MORT Leaf & MORT Stem & MORT Root \\
\hline needleleaf evergreen boreal tree & 0.8 & 0.5 & 0.0 & 0.5 & 0.5 & 0.9 & 0.8 & 0.1 \\
\hline broadleaf evergreen tropical tree & 0.8 & 0.5 & 0.0 & 0.6 & 0.6 & 0.9 & 0.8 & 0.1 \\
\hline broadleaf evergreen temperate tree & 0.8 & 0.5 & 0.0 & 0.6 & 0.6 & 0.9 & 0.8 & 0.1 \\
\hline broadleaf deciduous tropical tree & 0.8 & 0.5 & 0.0 & 0.6 & 0.6 & 0.9 & 0.6 & 0.1 \\
\hline broadleaf evergreen shrub & 0.8 & 0.5 & 0.0 & 0.6 & 0.6 & 0.9 & 0.6 & 0.1 \\
\hline broadleaf deciduous temperate shrub & 0.8 & 0.5 & 0.0 & 0.6 & 0.6 & 0.9 & 0.8 & 0.1 \\
\hline broadleaf deciduous boreal shrub & 0.8 & 0.5 & 0.0 & 0.6 & 0.6 & 0.9 & 0.8 & 0.1 \\
\hline c3 arctic grass & 0.9 & 0.0 & 0.0 & 0.7 & 0.7 & 0.9 & 0.0 & 0.25 \\
\hline c3 non-arctic grass & 0.9 & 0.0 & 0.0 & 0.7 & 0.7 & 0.9 & 0.0 & 0.25 \\
\hline $\mathrm{c} 4$ grass & 0.9 & 0.0 & 0.0 & 0.7 & 0.7 & 0.9 & 0.0 & 0.25 \\
\hline
\end{tabular}

by adding a woody combustion completeness factor $(0.2)$ that is applied to all woody fuel types. All other fuel types are completely combusted.

The amount of carbon released into the atmosphere for each PFT is given as:

$E_{\mathrm{PFT}}=f_{\Delta t} \cdot \boldsymbol{C} \cdot \mathrm{cc} \cdot \mathrm{mort}$

with $C=\left(C_{\text {leaf }}, C_{\text {stem }}, C_{\text {root }}, C_{\text {litter }}, C_{\text {cwd }}\right)$ being a vector of carbon concentrations in $\left[\mathrm{g} / \mathrm{m}^{2}\right]$ for the different fuel types considered in CLM-CN and cc and mort being a vector of combustion completeness and mortality factors, respectively, as defined in Tables A1 and A2. The amount of carbon killed during a fire and transferred to the litter pool for each PFT is given as:

$T_{\mathrm{PFT}}=f_{\Delta t} C(1-\mathrm{cc}) \mathrm{mort}$

Total carbon emission $\left(E_{\mathrm{c}}\right)$ are given as the area weighted sum over all PFTs. The same applies for nitrogen.

\section{A4 Human influence}

Humans influence fires by ignition (intentionally or accidentally) and at the same time they impact fires actively by fire suppression. To account for these effects we introduced a parametrization of the human ignition potential and fire suppression as a function of population density. Population density data were taken from the HYDE dataset for the years 


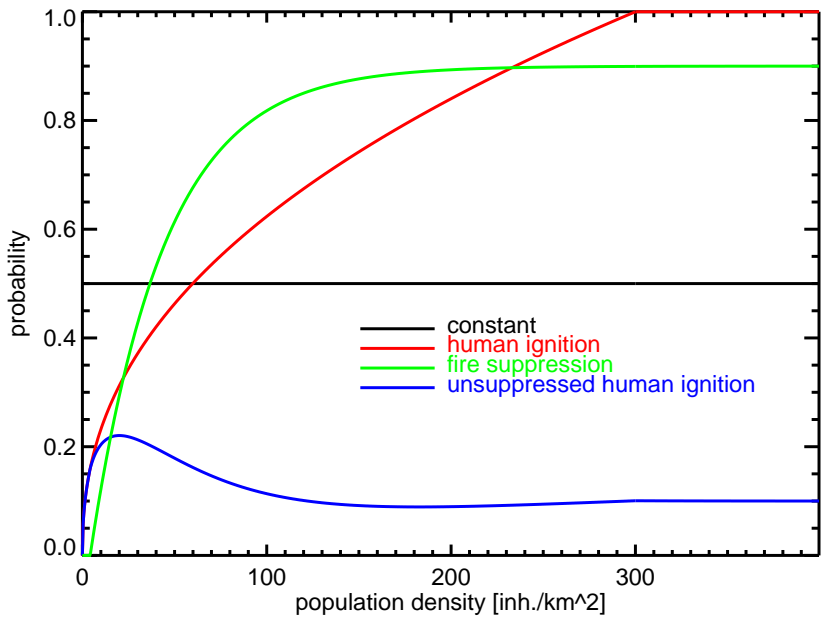

Fig. A1. Human ignition probability and fire suppression [01] as function of population density [inhabitants $/ \mathrm{km}^{2}$ ]. Black: constant ignition probability; red: Human ignition probability; green: fire suppression; blue: unsuppressed human ignition (human ignition·(1-fire suppression)).

1850-2000 (Klein Goldewijk, 2001). The population density was regridded from a $0.5^{\circ} \times 0.5^{\circ}$ resolution to the model resolution applied in this study $\left(1.9^{\circ} \times 2.5^{\circ}\right)$.

In an initial attempt the probability for human fire ignitions is assumed to be constant globally (0.5) as done in Arora and Boer (2005). To account more explicitly for human ignition probability we use the relationship given by Venesky et al. (2002) relating fire danger to population density (popd) in terms of interactions of humans with natural ecosystems (Fire danger $=6.8 \cdot$ popd $^{-0.57}$ ). This relationship assumes that an average person is more likely to cause a fire in sparsely populated regions, as they interact more with the natural ecosystems compared to persons living in densely populated areas. For densely populated regions we applied a lower threshold of 300 inhabitants $/ \mathrm{km}^{2}\left(\mathrm{pd}_{\mathrm{up}}\right)$. The human ignition probability is then given by:

$P_{\mathrm{h}}=\min \left(1, \operatorname{popd} \cdot 6.8 \cdot \operatorname{popd}^{-0.57} /\left(\mathrm{pd}_{\mathrm{up}} \cdot 6.8 \cdot \mathrm{pd}_{\mathrm{up}}^{-0.57}\right)\right)$

Fire suppression will also depend on the population density. Fire suppression will more likely take place in densely populated areas were typically high property values are at risk compared to sparsely populated areas (Stocks et al., 2003; Theobald and Romme, 2007). We parametrized fire suppression similar to Pechony and Shindell (2009) as follows:

$F_{\text {supp }}=1 .-(0.10+\exp (-0.025 \cdot$ popd $))$

assuming that in more densely populated areas $90 \%$ of the fires will be suppressed. Fire suppression will impact natural (lightning induced) fires as well as human initiated fires. The total ignition probability is then given as:

$P_{\mathrm{i}}=\left(P_{1}+\left(1-P_{1}\right) \cdot P_{\mathrm{h}}\right) \cdot\left(1 .-F_{\text {supp }}\right)$
Table A3. The redistribution of carbon and nitrogen upon conversion used in CLM-CN. Factors are based on Houghton et al. (1983).

\begin{tabular}{lccc}
\hline Ecosystem & $\begin{array}{c}\text { conversion } \\
\text { flux }\end{array}$ & $\begin{array}{c}\text { paper product } \\
\text { pool }\end{array}$ & $\begin{array}{c}\text { wood product } \\
\text { pool }\end{array}$ \\
\hline Temperate/boreal forest & 0.60 & 0.30 & 0.10 \\
Tropical forest & 0.60 & 0.40 & 0.00 \\
Grassland & 1.00 & 0.00 & 0.00 \\
Shrub lands & 0.80 & 0.20 & 0.00 \\
\hline
\end{tabular}

Figure A1 illustrates the human ignition probability as a function of population density. Unsuppressed human ignitions peak around $10-20$ inhabitants $/ \mathrm{km}^{2}$ which is in agreement with the analysis performed by Barbosa et al. (1999) for Africa.

Our parameterization of human ignition and fire suppression as a function of population density was an initial step to account for the human impact on fires in a global model. In reality, these anthropogenic impacts are much more complex. The effectiveness of fire suppression depends, for example, on how accessible a fire is to fire fighters and what fire management strategies are enforced (De Wilde and Chapin III, 2006). Human ignition critically depends not only on population, but also on socio-economic factors (Chuvieco et al., 2008). Higher spatial resolutions or the explicit inclusion of urban development (Jackson et al., 2010) will, for example, help to improve the representation of anthropogenic impacts. This should be explored in more detail in the future.

\section{A5 Deforestation fires}

To account for deforestation fires in CLM-CN we modified the current treatment of dynamic land cover within CLM$\mathrm{CN}$. Changes in land cover area over time were prescribed from an external dataset following the annual land cover change given by Hurtt et al. (2006) for the time period 1850 2004. Land cover change was given by an annual time series of globally gridded information about the subgrid fractional area occupied by the plant functional types (PFTs) within a grid-cell. The annual rate was equally distributed across the number of timesteps simulated in CLM-CN within a year. For the case that land cover change led to a reduction of the area occupied by a single PFT, the associated carbon and nitrogen loss was distributed into a wood production pool, paper production pool and a conversion flux. The allocation to the different pools is given in Table A3.

For the wood product pool we assumed a residence time of 100 years, for the paper production pool we assumed a residence time of 10 years and for the conversion flux we assumed this carbon was immediately released into the atmosphere. The conversion flux has a fire component in many regions that experience favorable burning conditions. We modified the CLM-CN scheme to account for the fraction of the 
1850 - no fire suppression

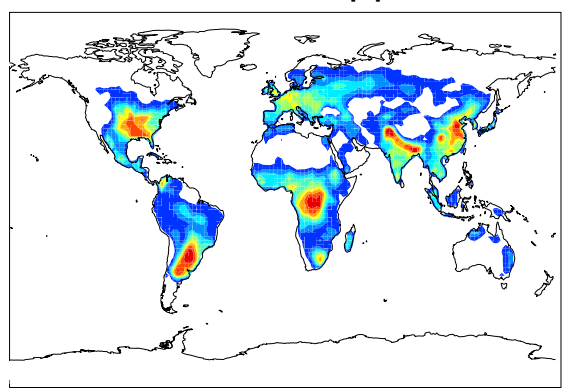

1850 - fire suppression

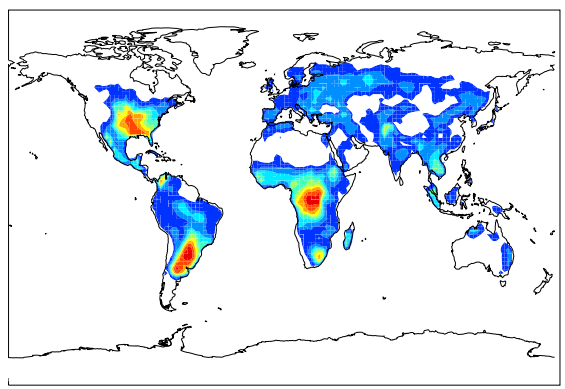

2000 - no fire suppression

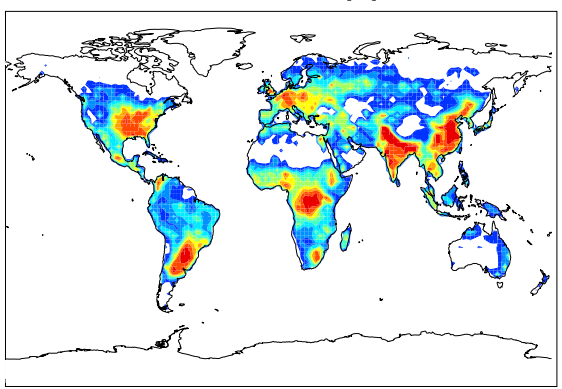

2000 - fire suppression

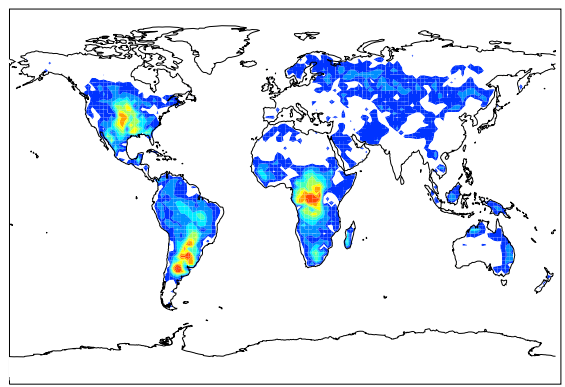

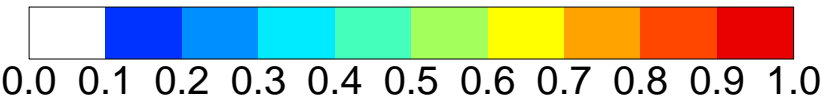

Fig. A2. Annual mean total ignition probability for the years 1850 and 2000 with and without fire suppression considered.

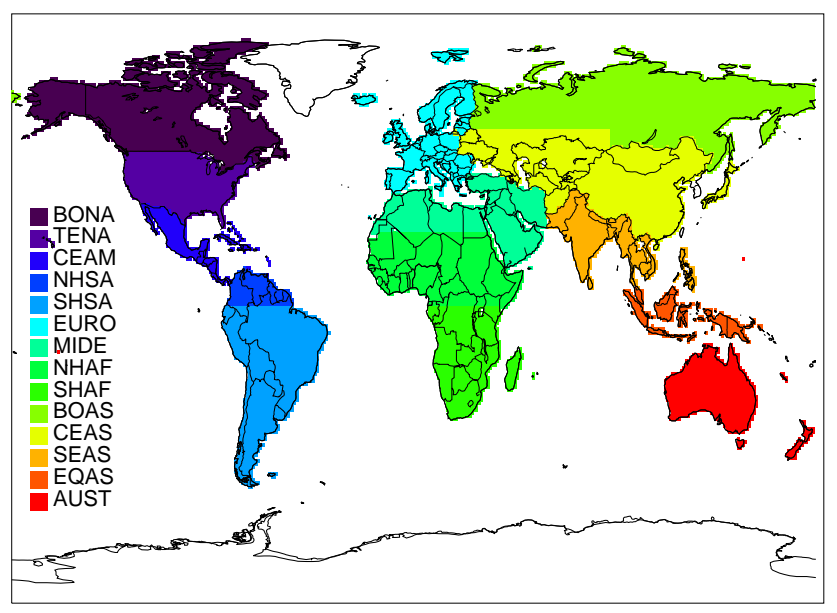

Fig. A3. Map of the 14 regions as defined in van der Werf et al. (2006) used in this study. BONA: Boreal North America, TENA: Temperate North America, CEAM: Central America, NHSA: Northern Hem. South America, SHSA: Southern Hem. South America, EURO: Europe, MIDE: Middle East, NHAF: Northern Hem. Africa, SHAF: Southern Hem. Africa, BOAS: Boreal Asia, CEAS: Central Asia, SEAS: Southeast Asia, EQAS: Equatorial Asia, AUST: Australia. conversion flux that was combusted (deforestation fires) as follows:

The conversion flux is divided into a fire and non-fire related pool. For this we define a fire-scalar (fs) as a function of the annual mean fire moisture probability $\left(P_{\mathrm{m} \text {,annual }}\right)$ simulated within the fire algorithm in CLM-CN (see Eqs. A1 and A7, respectively).

We assume that in regions with a high annual mean fire moisture probability, land managers will more likely burn forest biomass during the land clearing process. The firescalar is given as:

$$
\begin{gathered}
\mathrm{fs}=\mathrm{fs}_{\min }+\left(\operatorname { m a x } \left[0, \min \left(1,\left(P_{\mathrm{m}, \text { annual }}-\mathrm{fp}_{\text {low }}\right) /\right.\right.\right. \\
\left.\left.\left.\left(\mathrm{fp}_{\text {high }}-\mathrm{fp}_{\text {low }}\right)\right)\right]\right) \cdot\left(\mathrm{fs}_{\max }-f s_{\text {min }}\right)
\end{gathered}
$$

In an initial attempt we assumed that the maximum and minimum fraction of the conversion flux $\left(\mathrm{fs}_{\min }\right)$ and $\left(\mathrm{fs}_{\max }\right)$ that is redirected to the fire and non-fire pool are constant globally ( 0.2 and 0.8 , respectively). However, this ratio will also largely depend on cultural practices and is therefore likely to vary for different regions and different time periods.

Low and high annual mean moisture fire probabilities ( $\left.\mathrm{fp}_{\text {low }}\right)$ and (fp $\mathrm{p}_{\text {high }}$ ) were set to 0.01 and 0.30 , respectively. Annual mean moisture fire probabilities are below 0.01 for example in wet regions like northern Europe and the East 
coast of the USA, whereas values larger than 0.30 are simulated only in very dry regions such as Central Africa and Australia. Annual mean fire moisture probabilities slightly differed between the two fire algorithms applied in this study. However, we used the same thresholds for both.

The flux into the fire pool and non-fire pool is given as:

fire_pool gain $_{\text {gaNV }}=\mathrm{fs}$

non_fire_pool ${ }_{\text {gain }}=\mathrm{CONV} \cdot(1-\mathrm{fs})$

with CONV being the carbon and nitrogen mass flux attributed to the conversion flux.

The flux out of the fire-pool follows a rate constant, which is a function of the instantaneous fire moisture probability $\left(P_{\mathrm{m}, \text { inst }}\right)$ as simulated within the fire algorithm. Carbon in the fire-pool can accumulate over a certain time-period $\left(\tau_{\max }\right)$ in which conditions are relatively wet and is only released into the atmosphere when conditions get sufficiently dry (Morton et al., 2008; van der Werf et al., 2009). The rate constant which controls the flux out of the fire pool is given as:

$$
\begin{aligned}
\tau_{\text {fire }}= & \tau_{\min }+\max \left[0, \min \left(1,\left(P_{\mathrm{m}, \text { inst }}-\mathrm{fi}_{\text {low }}\right) /\left(\mathrm{fi}_{\text {high }}-\mathrm{fi}_{\text {low }}\right)\right)\right] \\
& \cdot\left(\tau_{\max }-\tau_{\min }\right)
\end{aligned}
$$

$\tau_{\min }$ and $\tau_{\max }$ are set to give a $90 \%$ loss of the initial mass of the fire-pool to be released into the atmosphere within 3 years and 1 week, respectively. $\mathrm{fi}_{\mathrm{low}}$ and fi $\mathrm{ingh}_{\text {igh }}$ are set to 0.0 and 1.0. The flux out of the non-fire pool into the atmosphere is immediate (fuel wood).

The flux out of the fire pool and non-fire pool is given as:

fire_pool $l_{\text {loss }}=$ fire_pool $\cdot \tau_{\text {fire }}$

non_fire_pool $l_{\text {loss }}=$ non_fire_pool $\cdot 1$.

with fire_pool and non_fire_pool representing the carbon and nitrogen mass in the fire and non-fire pool, respectively.

In addition to land cover change CLM-CN accounts explicitly for changes in wood harvest activity (Hurtt et al., 2006). Wood harvest is solely related to logging and is not directly related to fires. However, wood harvest will alter the biomass available for burning and thus natural fires as well as deforestation fires (see Sect. 5.1.3).

Acknowledgements. This work was supported by NSF-0758369, NSF-0832782, and NSF-0628353. For computational support the authors acknowledge the National Science Foundation (NSF) and the National Center for Atmospheric Research (NCAR). NCAR is sponsored by the NSF. We thank the participants and organizers of the AIMES workshop "Cultural Uses and Impacts of Fires" as well as S. Harrison, K. Thonicke and G. van der Werf for helpful discussion.

Edited by: E. Falge

\section{References}

Andreae, M. O., Rosenfeld, D., Artaxo, P., Costa, A. A., Grank, G. P., Longo, K. M., and Silva-Dias, M. A. F.: Smoking Rain Clouds over the Amazon, Science, 303, 1337-1342, 2004.

Arora, V. K. and Boer, G. J.: Fire as an interactive component of dynamic vegetation models, J. Geophys. Res., 110, G02008, doi:10.1029/2005JG000042, 2005.

Barbosa, P. M., Stroppiana, D., Gregoire, J.-M., and Pereira, J. M. C.: An assessment of vegetation fire in Africa (19811991): Burned areas, burned biomass, and atmospheric emissions, Global Biogeochem. Cycles, 13, 933-950, 1999.

Bond, W. J., Woodward, F., and Midgley, G. F.: The global distribution of ecosystems in a world without fire, New Phytologist, 165, 525-538, doi:10.1111/j.1469-8137.2004.01252.x, 2004.

Boschetti, L., Eva, H. D., Brivio, P. A., and Gregoire, J. M.: Lessons to be learned form the comparison of three satellite-derived biomass burning products, Geophys. Res. Lett., 31, L21501, doi:10.1029/2004GL021229, 2004.

Bowman, D. M. J. S., Balch, J. K., Artaxo, P., Bond, W. J., Carlson, J. M., Cochrane, M. A., D'Antonio, C. M., DeFries, R. S., Doyle, J. C., Harrison, S. P., Johnston, F. H., Keeley, J. E., Krawchuk, M. A., Kull, C. A., Marston, J. B., Mortiz, M. A., Prentice, I. C., Roos, C. I., Scott, A. C., Swetnam, T. W., van der Werf, G. R., and Pyne, S. J.: Fire in the Earth System, Science, 324, 481, doi:10.1126/science.1163886, 2009.

Chambers, S. D., Beringer, J., Randerson, J. T., and Chapin III, F. S.: Fire effects on net radiation and energy partitioning: Contrasting responses of tundra and boreal forest ecosystems, J. Geophys. Res., 110, D09106, doi:10.1029/2004JD2005299, 2005.

Chang, D. and Song, Y.: Comparison of L3JRC and MODIS global burned area products from 2000 to 2007, J. Geophys. Res., 114, D16106, doi:10.1029/2008JD011361, 2009.

Chuvieco, E., Giglio, L., and Justice, C.: Global parameterization of fire activity: toward defining fire regimes from Earth observation data, Glob. Change Biology, 14, 1488-1502, doi:10.1111/j.13652486.2008.04585.x, 2008.

Crutzen, P., Heidt, L. E., Krasnec, J. P., Pollock, W. H., and Seiler, W.: Biomass burning as a source of atmospheric gases $\mathrm{CO}, \mathrm{H}_{2}, \mathrm{~N}_{2} \mathrm{O}, \mathrm{NO}, \mathrm{CH}_{3} \mathrm{CL}$ and COS, Nature, 282, 253-256, doi:10.1038/282253a0, 1979.

De Wilde, L. and Chapin III, F.: Human impact on the fire regime of interior Alaska: Interactions among fuels, ignition sources, and fire suppression, Ecosystems, 9, 8, doi:10.1007/ s10021-006-0095-0, 2006.

Decker, R. M. and Zeng, X.: Impact of modified richards equation on global soil moisture simulation in the Community Land Model (CLM3.5), J. Adv. Model. Earth Syst., 1, doi:10.3894/JAMES.2009.1.5, 2009.

Duncan, B. N., Martin, R. V., Staudt, A. C., Yevich, R., and Logan, J. A.: Interannual and seasonal variability of biomass burning emissions constrained by satellite observations, J. Geophys. Res., 108, D24100, doi:10.1029/2002JD002378, 2003.

Feingold, G., Remer, L. A., Ramaprasad, J., and Kaufman, Y. J.: Analysis of smoke impact on clouds in Brazilian biomass burning regions: An extension of Twomey's approach, J. Geophys. Res., 103, 22907-22922, 2001.

Flanner, M. G. and Zender, C. S.: Snowpack radiative heating: Influence on Tibetan Plateau climate, J. Geophys. Res., 32, L06501, doi:10.1029/2004GL022076, 2005. 
Flanner, M. G. and Zender, C. S.: Linking snowpack microphysics and albedo evolution, J. Geophys. Res., 111, D12208, doi:10.1029/2005JD006834, 2006.

Flanner, M. G., Zender, C. S., Randerson, J. T., and Rasch, P. J.: Present-day climate forcing and response from black carbon in snow, J. Geophys. Res., 112, D11202, doi:10.1029/2006JD008003, 2007.

Geist, H.: What drives tropical deforestation? A meta-analysis of proximate and underlying causes of deforestation based on subnational case study evidence, in: Land-Use and LandCover Change (LUCC) Project Report Series, edited by International Human Dimensions Programme on Global Environmental Change (IHDP), I. G.-B. P. I., vol. 4, 2001.

Giglio, L., van der Werf, G. R., Randerson, J. T., Collatz, G. J., and Kasibhatla, P.: Global estimation of burned area using MODIS active fire observations, Atmos. Chem. Phys., 6, 957974, doi:10.5194/acp-6-957-2006, 2006.

Giglio, L., Randerson, J. T., van der Werf, G. R., Kasibhatla, P. S., Collatz, G. J., Morton, D. C., and DeFries, R. S.: Assessing variability and long-term trends in burned area by merging multiple satellite fire products, Biogeosciences, 7, 1171-1186, doi:10.5194/bg-7-1171-2010, 2010.

Goldammer, J. and Seibert, B.: The impact of droughts and forest fires on tropical low land rain forest of Eastern Borneo, in: Fire in the tropical biota. Ecosystems processes and global challenges, edited by: Goldammer, J. G., Ecological Studies 84, pp. 11-31, Springer-Verlang, Berlin-Heildelberg-New York, 1990.

Gregoire, J.-M., Tansey, K., and Silva, J. M. N.: The GBA2000 initiative: Developing a global burned area database from SPOTVEGETATION imagery, Int. J. Remote Sens., 24, 1369-1376, 2002.

Guyette, R. P., Musika, R. M., and Dey, D. C.: Dynamics of an anthropogenic fire regime, Ecosystems, 5, 472-486, doi:10.1007/s10021-002-0115-7, 2002.

Hansen, M. C., Sheman, S. V., Potapov, P. V., Loveland, T. R., Townshend, J. R. G., DeFries, R. S., Pittman, K. W., Arunarwati, B., Stolle, F., Steininger, M. K., Caroll, M., and DiMiceli, C.: Humid tropical forest clearing from 2000 to 2005 quantified by using multitemporal and multiresolution remotely sensed data, PNAS, 105, 9439-9444, 2008.

Hoffa, E. A., Ward, D. E., Hao, W. M., Susott, R. A., and Wakimoto, R. H.: Seasonality of carbon emissions from biomass burning in a Zambian savanna, J. Geophys. Res., 104, 13841-13853, 1999.

Houghton, R. A., Hobbie, J. E., Melillo, J. M., Morre, B., Peterson, B. J., Shaver, G. R., and Woodwell, G. M.: Changes in the carbon content of terrestial biota and soils between 1860 and $1980-\mathrm{A}$ net release of $\mathrm{CO}_{2}$ to the atmosphere, Ecol. Monogr., 53, 235262, 1983.

Hurtt, G. C., Frolking, S., Fearon, M. G., Morre, B., Shevliakova, E., Malyshev, S., Pacala, S. W., and Houghton, R. A.: The underpinnings of land-use history: three centuries of global gridded land-use transitions, wood harvest activity, and resulting secondary lands, Glob. Change Biology, 12(7), 1208-1229, doi:10.1111/j.1365-2486.2006.01150.x, 2006.

Ito, A. and Penner, J. E.: Global estimates of biomass burning emissions based on satellite imagery for the year 2000, J. Geophys. Res., 109, D14S05, doi:10.1029/2003JD004423, 2004.

Ito, A. and Penner, J. E.: Historical emissions of carbonaceous aerosols from biomass and fossil fuel burning for the period
1870-2000, Global Biogeochem. Cycles, 19, 2005.

Ito, A., Ito, A., and Akimoto, H.: Seasonal and interannual variations in $\mathrm{CO}$ and $\mathrm{BC}$ emissions from open biomass burning in Southern Africa during 1998-2005, Global Biogeochem. Cycles, 21, GB2011, doi:10.1029/2006GB002848, 2007.

Ito, A., Penner, J. E., Prather, M. J., de Campos, C. P., Houghton, R. A., Kato, T., Jain, A. K., Yang, X., Hurtt, G. C., Frolking, S., Fearon, M. G., Chini, L. P., Wang, A., and Price, D. T.: Can we reconcile differences in estimates of carbon fluxes from landuse change and forestry for the 1990s?, Atmos. Chem. Phys., 8, 3291-3310, doi:10.5194/acp-8-3291-2008, 2008.

Jackson, T., Feddeman, J., Oleson, K., Bonan, G., and Bauer, J.: Parameterization of urban characteristics for global climate modeling, A. Assoc. Am. Geog., in press, 2010.

Kasischke, E. S. and Bruhwiler, L. P.: Emissions of carbon dioxide, carbon monoxide, and methane from boreal forest fires in 1998, J. Geophys. Res., 108, D18146, doi:10.1029/2001JD000461, 2003.

Kasischke, E. S. and Penner, J. E.: Improving global estimates of atmospheric emissions from biomass burning, J. Geophys. Res., 109, D14S01, doi:10.1029/2004JD004972, 2004.

Klein Goldewijk, K.: Estimating global land use change over the past 300 years, Global Biogeochem. Cycles, 15, 417-433, 2001.

Kreidenweis, S. M., Remer, L. A., Bruintjes, R., and Dubovik, O.: Smoke aerosol from biomass burning in Mexico: Hygroscopic smoke optical model, J. Geophys. Res., 106, 4831-4844, 2001.

Lamarque, J. F., Kiehl, J., Brasseur, G., Butler, T., Cameron-Smith, P., Collins, W. D., Collins, W. J., Granier, C., Hauglustaine, D., Hess, P., Holland, E., Horowitz, L., Lawrence, M., McKenna, D., Merilees, P., Prather, M., Rasch, P., Rotman, D., Shindell, D., and Thornton, P.: Assessing future nitrogen deposition and carbon cycle feedbacks using a multi-model approach: Analysis of nitrogen deposition, J. Geophys. Res., 110, D19303, doi:10.1029/2005JD005825, 2005.

Lawrence, D. M. and Slater, A. G.: Incoporating organic soil into a global climate model, Clim. Dynam., 30, 2-3, doi:10.1007/s00382-007-0278-1, 2008a.

Lawrence, D. M. and Slater, A. G.: The contribution of snow condition trends to future ground climate, Clim. Dynam., 34, 7-8, doi:10.1007/s00382-009-0537-4, 2009.

Lawrence, D. M., Slater, A. G., Roanovsky, V. E., and Nicolsky, D. J.: Sensitivity of a model projection of near-surface permafrost degradation to soil column depth and representation of soil organic matter, J. Geophys. Res., 113, F02011, doi:10.1029/2007JF000883, 2008b.

Lawrence, P. J. and Chase, T. N.: Representing a new MODIS consistent land surface in the Community Land Model (CLM 3.0), J Geophys. Res., 112, G01023, doi:10.1029/2006JG00016, 2007.

Lehsten, V., Tansey, K., Balzter, H., Thonicke, K., Spessa, A., Weber, U., Smith, B., and Arneth, A.: Estimating carbon emissions from African wildfires, Biogeosciences, 6, 349-360, doi:10.5194/bg-6-349-2009, 2009.

LIS/OTD: Lightning Imaging Sensor/Optical Transient Detector: NASA LIS/OTD Science Team (Principal Investigator, H. J. Christian, NASA/Marshall Space Flight Center), available from the Global Hydrology Resource Center (http://ghrc.msfc.nasa.gov).

Liu, H. and Randerson, J. T.: Interannual variability of surface energy exchange depends on stand age in a boreal for- 
est fire chronosequence, J. Geophys. Res., 113, G01006, doi:10.1029/2007JG000483, 2008.

Marlon, J. R., Bartlein, P. J., Carcaillet, C., Gavin, D. G., Higuera, P. E., Joos, F., Power, M. J., and Prentice, I. C.: Climate and human influences on global biomass burning over the past two millennia, Nature Geosci., 1, doi:10.1038/ngeo313, 2008.

Mieville, A., Granier, C., Liousse, C., Guillaume, B., Mouillot, F., Lamarque, J. F., Gregoire, J. M., and Petron, G.: Emissions of gases and particles from biomass burning during the 20th century using satellite data and a historical reconstruction, online available at: http://www.aero.jussieu.fr/projet/ACCENT/GICC.php, last access: January 2010, Atmos. Environ., 44(11), 1469-1477, doi:10.1016/j.atmosenv.2010.01.011, 2010.

Morton, D., DeFries, R. S., Shimabukuro, Y. S., Anderson, L. O., Arai, E., del Bon Espirio-Santo, F., Freitas, R., and Morisette, J.: Cropland expansion changes deforestation dynamics in southern Brazil Amazon, PNAS, 103, 14637-14641, 2006.

Morton, D. C., DeFries, R. S., Randerson, J. T., Giglio, L., Schroeder, W., and van der Werf, G. R.: Agricultural intensification increases deforestation fire activity in Amazonia, Global Change Biology, 14, 2262-2275, 2008.

Mouillot, F., Narasimha, A., Balkansji, Y., and Lamarque, J.-F.: Global carbon emissions from biomass burning in the 20th century, Geophys. Res. Lett., 33, L01801, doi:10.1029/2005GK024707, 2006.

Niu, G.-Y. and Yang, Z.-L.: An observation-based formulation of snow cover fraction and its evaluation over large North American river basins, J. Geophys. Res., 112, D21101, doi:10.1029/2007JD008674, 2007.

Oleson, K. W., Niu, G.-Y., Yang, Z.-L., Lawrence, D. M., Thornton, P. E., Lawrence, P. J., Stoeckli, R., Dickinson, R. E., Bonan, G. B., Levis, S., Dai, A., and Qian, T.: Improvements to the Community Land Model and their impact on the hydrological cyle., J. Geophys. Res., 113, G01021, doi:10.1029/2007JG000563, 2008a.

Oleson, K. W., Bonan, G. B., Feddema, J., Vertenstein, M., and Grimmong, C. S. B.: An urban paramterization for a global climate model. 1. Formulation and evaluation of two cities, J. Appl. Meteorol. Clim., 47, 1038-1060, 2008b.

Page, S. E., Siegert, F., Rieley, J. O., Boehm, H.-D. V., Jaya, A., and Limin, S.: The amount of carbon released from peat and forest fires in Indonesia during 1997, Nature, 420, 61-64, 2002.

Pechony, O. and Shindell, D. T.: Fire parameterization on a global scale, J. Geophys. Res., 114, D16115, doi:10.1029/2009JD011927, 2009.

Penner, J. E., Dickison, R. E., and O'Neill, C. A.: Effects of aerosol form biomass burning on the global radiation budget, Science, 256, 1432-1434, doi:10.1126/science.256.5062.1432, 1992.

Pierce, E. T.: Latitudinal Variation of Lightning Parameters, J. of Applied Meteorology, pp. 164-165, 1969.

Plummer, S., Arino, O., Simon, M., and Steffen, W.: Establishing an earth observation product service for the terrestrial carbon community: the GLOBCARBON initiative, Mitigation and adaptation strategies for global change, 11, 97-111, 2006.

Power, M. J., Marlon, J., Ortiz, N., Bartlein, P. J., Harrison, S. P., E., M. F., Ballouche, A., Bradshaw, R. H. W., Carcaillet, C., Cordova, C., Mooney, S., Moreno, P. I., Prentice, I. C., Thonicke, K., Tinner, W., Whitlock, C., Zhang, Y., Zhao, Y., Ali, A. A., Anderson, R. S., Beer, R., Behling, H., Briles, C., Brown, K. J.,
Brunelle, A., Bush, M., Camill, P., Chu, G. Q., Clark, J., Colombaroli, D., Connor, S., et al.: Changes in fire regimes since the Last Glacial Maximum: an assessment based on a global synthesis and analysis of charcoal data, Clim. Dynam., 30, 887-907, doi:10.1007/s00382-007-0334-x, 2008.

Qian, T., Dai, A., Trenberth, K. E., and Oleson, K. W.: Simulation of global land surface conditions from 1948 to 2004. Part I: Forcing Data and Evaluations, American Met. Soc., 7, 953-975, 2006.

Ramankutty, N., Evan, A., Monfreda, C., and Foley, J. A.: Farming the Planet. Part 1: The Geographic Distribution of Global Agricultural Lands in the Year 2000, Global Biogeochem. Cycles, 22, GB1003, doi:10.1029/2007GB002952, 2008.

Randerson, J. T., Hoffman, F. M., Thornton, P. E., Mahowald, N. M., Lindsay, K., Lee, Y.-H., Nevison, C. D., Doney, S. C., Bonan, G., Stoeckli, R., Covey, C., Running, S. W., and Fung, I. Y.: Systematic assessment of terrestial biogeochemistry in coupled climate-carbon models, Global Change Biol., 15, 2462-2484, doi:10.1111/j.1365-2486.2009.01912.x, 2009.

Robin, J.-G., Carrega, P., and Fox, D. M.: Modelling fire ignition in the Alpes-Maritimes Department, France, A comparison, For Ecol. Manage., 234, 1, doi:10.1016/j.foreco.2006.08.176, 2006.

Roy, D. P. and Boschetti, L.: Southern Africa Validation of the MODIS, L3JRC, and GlobCarbon Burned-area Products, IEEE - Geosci. Rem. Sens., 47, 4, doi:10.1109/TGRS.2008.2009000, 2009.

Roy, D. P. P., Boschetti, L., Justice, C. O., and Ju, J.: The Collection 5 MODIS burned area product - Global evaluation by comparison with the MODIS active fire product, Rem. Sens. Environ. 112, 3690-3707, doi:10.1016/j.rse.2008.05.013, 2008.

Sakaguchi, K. and Zeng, X.: Effects of soil wetness, plant litter, and under-canopy atmospheric stability on ground evaporation in the Community Land Model (CLM3.5), J. Geophys. Res., 114, D01107, doi:10.1029/2008JD010834, 2009.

Schultz, M. G., Heil, A., Hoelzemann, J. J., Spessa, A., Thonicke, K., Goldammer, J. G., Held, A. C., Pereira, J. M. C., and van het Bolscher, M.: Global wildland fire emissions from 1960 to 2000, Global Biogeochem. Cycles, 22, GB2002, doi:10.1029/2007GB03031, 2008.

Shevliakova, E., Pacala, S. W., Malyshev, S., Hurtt, G. C., Milly, P. C. D., Caspersen, J. P., Sentman, L. T., Fisk, J. P., Wirth, C., and Crevoisier, C.: Carbon cycling under 300 years of land use change: Importance of the secondary vegetation sink, Global Biogeochem. Cycles, 23, GB2022, doi:10.1029/2007GB003176, 2009.

Simon, M., Plummer, S., Fierens, F., Hoelzemann, J. J., and Arino, O.: Burnt area detection at global scale using ATSR-2: The GLOBSCAR products and their qualification, J. Geophys. Res., 109, D14S02, doi:10.1029/2003JD003622, 2004.

Sitch, S., Smith, B., Prentice, I. C., Arneth, A., Bondeau, A., Cramer, W., Kaplan, J. O., Levis, S., Lucht, W., Sykes, M. T., Thonicke, K., and Venesky, S.: Evaluation of ecosystem dynamics, plant geography and terrestrial carbon cycling in the LPJ Dynamic Global Vegetation Model, Global Change Biol., 9, 161185, 2003.

Smith, B., Prentice, I. C., and Sykes, M. T.: Representation of vegetation dynamics in the modelling of terrestial ecosystems: comparing two contrasting approaches within European climate space, Global Ecol. Biogeogr., 10, 621-637, 2001. 
Soja, A. J., Cofer, W. R., Shugart, H. H., Sukhinin, A. I., Stackhouse, Jr., P. W., McRae, D. J., and Conrad, S. G.: Estimating fire emissions and disparities in boreal Siberia (1998-2002), J. Geophys. Res., 109, D14S06, doi:10.1029/2004JD004570, 2004.

Stern, D. I. and Kaufmann, R. K.: Estimates of global anthropogenic methane emissions 1860-1993, Chemosphere, 33, 159176, 1996.

Stocks, B. J., Mason, J. A., Todd, J. B., Bosch, E. M., Wotton, B. M., Amiro, B. D., Flannigan, M. D., Hirsch, K. G., Logan, K. A., Martell, L. D., and Skinner, W. R.: Large forest fires in Canada, 1959-1997, J. Geophys. Res., 108, D18149, doi:10.1029/2001JD000484, 2003.

Stoeckli, R., Lawrence, D. M., Niu, G.-Y., Oleson, K. W., Thornton, P. E., Yang, Z.-L., Bonan, G. B., Denning, A. S., and Running, S. W.: The use of Fluxnet in the Community Land Model development, J. Geophys. Res., 113, G01025, doi:10.1029/2007JG000562, 2008.

Tansey, K., Gregoire, J.-M., Defourny, P., Leigh, R., Pekel, J.-F., van Bogaert, E., and Baerholome, E.: A new, global, multiannual (2000-2007) burnt area product at $1 \mathrm{~km}$ resolution, Geophys. Res. Lett., 35, L01401, doi:10.1029/2007GL031567, 2008.

Theobald, M. T. and Romme, W. H.: Expansian of the US wildland-urban interface, Landsc. Urban Plan., 83, 340-354, doi:10.1016/j.landurbplan.2007.06.002, 2007.

Thonicke, K., Venesky, S., Sitch, S., and Cramer, W.: The role of fire disturbance for global vegetation dynamics: coupling fire into a Dynamic Global Vegetation Model, Global Ecol. Biogeogr., 10, 661-667, 2001.

Thornton, P. E. and Rosenbloom, N. A.: Ecosystem model spinup: estimating steady state conditions in a coupled terrestial carbon and nitrogen cycle model, Ecological Modelling, pp. 25-48, 2005.

Thornton, P. E., Law, B. E., Gholz, H. L., Clark, K. L., Falge, E., Ellsworth, D. S., Goldstein, A. H., Moson, R. K., Hollinger, D., Falk, M., Chen, J., and Sparks, J. P.: Modeling and measuring the effects of disturbance history and climate on carbon and water budgets in evergreen needleleaf forests, Agricultural and Forest Meteorology, 113, 185-222, 2002.
Thornton, P. E., Lamarque, J. F., Rosenbloom, N. A., and Mahowald, N. M.: Influence of carbon-nitrogen cycle coupling on land model response to $\mathrm{CO}_{2}$ fertilization and climate variability, Global Biogeochem. Cycles, 21, GB4018, doi:1029/2006GB002868, 2007.

Thornton, P. E., Doney, S. C., Lindsay, K., Moore, J. K., Mahowald, N., Randerson, J. T., Fung, I., Lamarque, J.-F., Feddema, J. J., and Lee, Y.-H.: Carbon-nitrogen interactions regulate climate-carbon cycle feedbacks: results from an atmosphereocean general circulation model, Biogeosciences, 6, 2099-2120, doi:10.5194/bg-6-2099-2009, 2009.

van der Werf, G. R., Randerson, J. T., Giglio, L., Collatz, G. J., Kasibhatla, P. S., and Arellano Jr., A. F.: Interannual variability in global biomass burning emissions from 1997 to 2004, Atmos. Chem. Phys., 6, 3423-3441, doi:10.5194/acp-6-3423-2006, 2006.

van der Werf, G. R., Morton, D. C., DeFries, R. S., Giglio, L., Randerson, J. T., Collatz, G. J., and Kasibhatla, P. S.: Estimates of fire emissions from an active deforestation region in the southern Amazon based on satellite data and biogeochemical modelling, Biogeosciences, 6, 235-249, doi:10.5194/bg-6-235-2009, 2009.

Venesky, S., Thonicke, K., Sitch, S., and Cramer, W.: Simulating fire regimes in human-dominated ecosystems: Iberian Peninsula case study, Global Change Biology, 8, 984-998, 2002.

Verseghy, D., McFarlane, N. A., and Lazare, M.: CLASS - A Canadian land surface scheme for GCMs: II. Vegetation model and coupled runs, Int. J. Climatol., 13, 347-370, 1993.

Wang, A. H. and Zeng, X. B.: Improving the treatment of the vertical snow burial fraction over short vegetation in the NCAR CLM3, Adv. Atmos. Sci., 26, 5, doi:10.1007/s00376-009-80983, 2009 .

Westerling, A. L., Gershunov, A., Brown, T. J., Cayan, D. R., and Dettinger, M. D.: Climate and wildfire in the western United States, B. Am. Meteorol. Soc., 84, 5, doi:10.1175/ BAMS-84-5-595, 2003. 